\title{
Intelligent energy systems
}

\section{Larsen, Hans Hvidtfeldt; Sønderberg Petersen, Leif}

\section{Published in:}

DTU Climate Change Technologies

Publication date:

2009

\section{Document Version}

Publisher's PDF, also known as Version of record

Link back to DTU Orbit

Citation (APA):

Larsen, H. H., \& Sønderberg Petersen, L. (2009). Intelligent energy systems. In N. A. Nielsen, H. H. Larsen, K. Halsnæs, J. F. Hansen, \& I. Frøkjær Strand (Eds.), DTU Climate Change Technologies: Recommendations on accelerated development and deployment of climate change technologies (pp. 16-17). Technical University of Denmark.

\section{General rights}

Copyright and moral rights for the publications made accessible in the public portal are retained by the authors and/or other copyright owners and it is a condition of accessing publications that users recognise and abide by the legal requirements associated with these rights.

- Users may download and print one copy of any publication from the public portal for the purpose of private study or research.

- You may not further distribute the material or use it for any profit-making activity or commercial gain

- You may freely distribute the URL identifying the publication in the public portal

If you believe that this document breaches copyright please contact us providing details, and we will remove access to the work immediately and investigate your claim 


\section{DTU Climate Change Technologies}

Recommendations on accelerated development and deployment of climate change technologies 



\section{Contents}

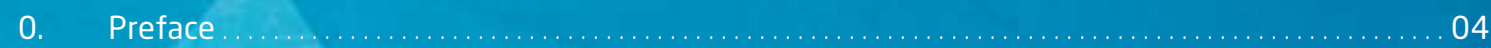

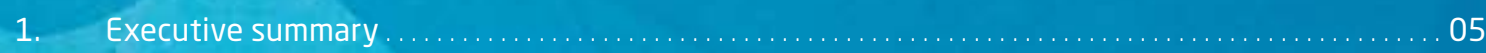

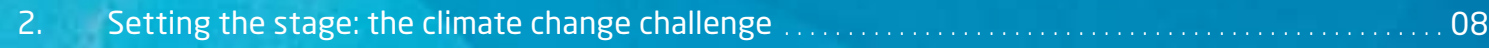

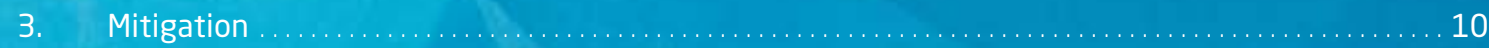

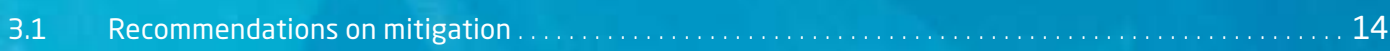

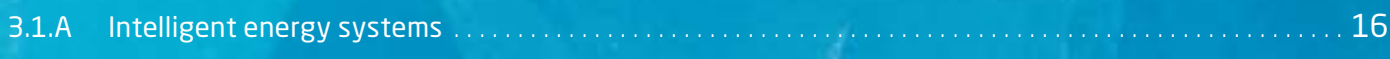

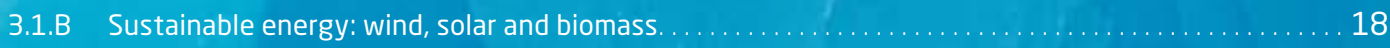

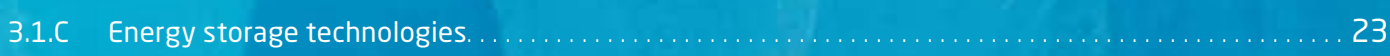

3.1.D Low-emission combustion technologies .................................. 25

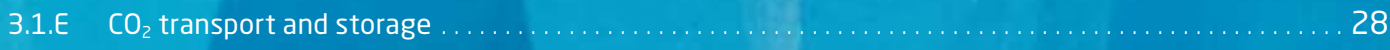

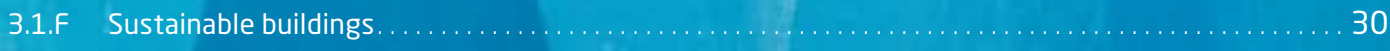

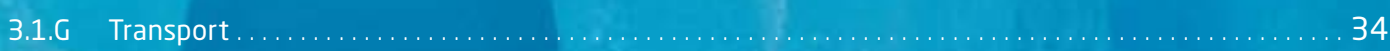

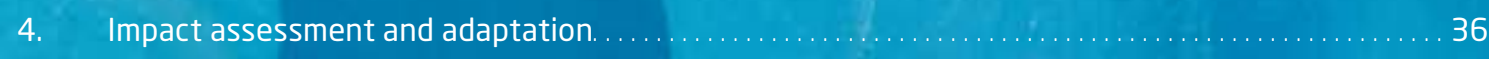

4.1 Recommendations on impact assessment and adaptation $\ldots \ldots \ldots \ldots \ldots \ldots \ldots \ldots \ldots \ldots \ldots \ldots \ldots \ldots \ldots \ldots \ldots$

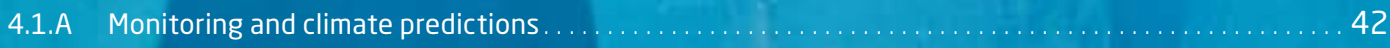

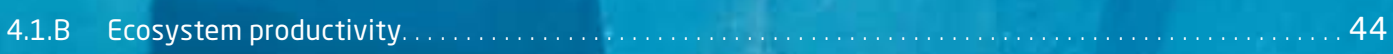

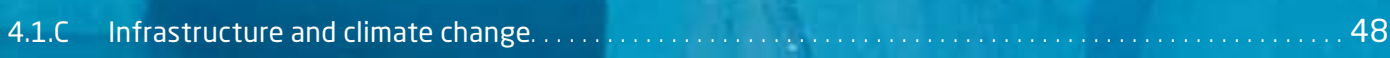

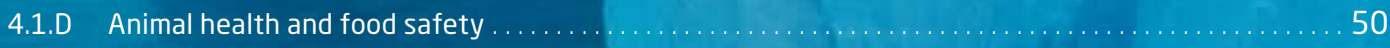

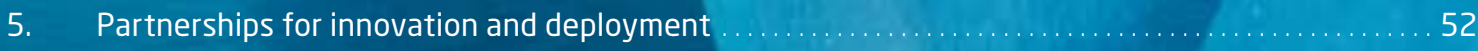

$5.1 \quad$ Rules and regulations set by public authorities $\ldots \ldots \ldots \ldots \ldots \ldots \ldots \ldots \ldots \ldots \ldots \ldots \ldots \ldots \ldots \ldots \ldots \ldots \ldots \ldots \ldots$

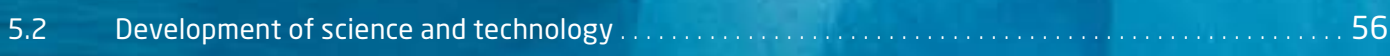

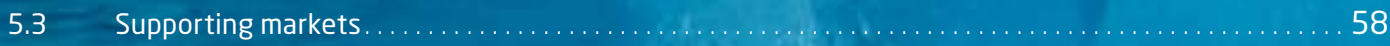

$5.4 \quad$ Improving networks and alliances: coordinating efforts, resources and capability . . . . . . . . . . 59 


\section{Preface}

An important step towards increased awareness and understanding of the risks related to global climate change was made when the Intergovernmental Panel on Climate Change published the Fourth Assessment Report in 2007. At the United Nations Climate Change Conference (COP 15) to be held in Copenhagen in December 2009, decision-makers have to take the next important step to ensure that the global atmospheric greenhouse-gas concentrations will be stabilized over the next centuries and that the effects of global climate change will be limited.

In 2008, DTU established the program DTU Climate Change Technologies to develop and strengthen its contribution to solving the climate challenge during the next decades. The primary objective of the program is to ensure that DTU contributes significantly to developing and implementing new solutions related to climate change.
During 2008 and 2009, DTU Climate Change Technologies organized 10 workshops with representatives from science, business and public authorities covering fields of technology related to mitigation, impact assessment and adaptation. The workshops will conclude with the DTU Climate Change Technologies Conference on September 17, 2009. Each workshop gave an overview of a specific field and outlined recommendations on specific types of technology, and the DTU Climate Change Technologies Conference will address cross-cutting issues and make broader recommendations for accelerated development and deployment of climate change technologies.

This conference paper summarizes the output of each workshop covering fields of technology related to mitigation, impact assessment and adaptation and makes recommendations that contribute to the strategic foundation of DTU and partners in tackling the climate challenge over the next decades. In addition, this conference paper is a contribution to the United Nations Climate Change Conference in Copenhagen in December 2009 to highlight opportunities and challenges in implementing climate change technologies as part of a globally coordinated effort to meet the climate change challenge. 


\section{Executive summary}

The Fourth Assessment Report of the Intergovernmental Panel on Climate Change (IPCC) concludes that global temperature increases exceeding $2^{\circ} \mathrm{C}$ more than preindustrial levels could impose great risks, and several groups of countries have advocated a climate policy objective set at this level during the preparatory process for the United Nations Climate Change Conference in Copenhagen in December 2009 (COP 15). It has been suggested that this can be met by reducing global greenhouse-gas emissions by $50 \%$ in 2050 and reducing them by $80-100 \%$ in industrialized countries in 2050 . By the end of the century, such a reduction should have taken place in all countries.

Consequently, the challenge is to develop and implement technology and processes that decouple economic activity and greenhouse-gas emissions in industrialized countries by 2050 and in all countries by the end of the century.

Even if the technology transition succeeds and the target reduction is met, the climate will change in the coming decades, and societal planning and management of all key sectors must be adapted to the new climate conditions. In addition, solutions need to take into account predicted population growth to 9 billion, demographic changes, shortage of key resources such as water, food supply and health aspects.

The workshops focused on sustainable energy systems and climate change adaptation. The summary of conclusions and recommendations from the workshops constitutes a comprehensive set of technology tracks and recommended actions towards accelerated development and deployment of technology within these two key areas. The workshop process has led to three main conclusions.

A. Radical changes are needed to develop sustainable energy systems.

B. Tools and processes that climate-proof societal planning and management are needed in order to adapt to climate change.

C. Partnerships concerning innovation and deployment (research, development and deployment) are required to meet time constraints.

\section{A. Sustainable energy systems}

Energy systems must be radically changed. Although the specific design will evolve and change and cannot currently be described in detail, three robust conclusions on system design and operation can be drawn. Intelligent energy systems are needed, the use of zero- or

low-emission energy sources must be radically enhanced and efficiency must be improved massively, especially in the transport and building sectors.

\section{Intelligent energy systems}

Energy systems have to be developed into intelligent systems that integrate all main energy producers and users at the regional level to accommodate a high share of renewable energy provided by a multitude of variable technologies. Overall energy efficiency must be ensured by the ability to manage the interaction between the various supply technologies and end-use through wide use of two-way communication systems. Buildings must be an integral part of overall energy systems, as they will both produce and use energy. Further, the transport sector has to be integrated into energy systems to increase the share of fuels based on renewable energy. These future energy systems will have an increasing need for storing energy, determined by the mix of energy sources and the ability to shift demand. Integrated and intelligent energy systems including the end-use sectors will enable the systems to be optimized as a whole.

\section{Zero- and low-emission energy sources}

Renewable energy sources must be promoted as far as possible. Three main sources, wind, solar and biomass, have strong potential to contribute. ${ }^{1}$ If a concerted and targeted development and deployment effort is made, renewable sources can cover a substantial part of the energy needed in 2050. However, high-efficiency fossil-fuel combustion technology and carbon capture and storage technology need to be developed to meet this objective globally. 
Wind power has proven to be a mature technology and shows strong potential in global electricity production. To ensure high generation from wind power, research, development and deployment should focus on turbine technology, improving efficiency, reducing costs and improving the grid interface. In addition, concerted action and improved collaboration is needed to accelerate the deployment of wind parks.

Solar energy can become a major component of future sustainable energy supply in the form of solar thermal heating and cooling and electricity generation by photovoltaics or concentrating solar power. Electricity generation technologies, especially photovoltaics, require substantial research and development to improve efficiency and to reduce costs. The various solar energy technologies have broad and diverse application, and the technology related to grid connection and system integration needs to be developed.

Bioenergy has a high share of current renewable energy supply. It is flexible and can be produced from a variety of feedstocks such as waste and crops. The limitation is mainly due to competition in land use for food production, and sustainable system assessment must be carried out. Increased amounts of biomass might be used as fuel in power plants or converted to fuel for the transport sector via biorefinery processes. Biofuels might be one of the few options for sustainable fuel for air transport.

Carbon capture and storage in electrical power plants and $\mathrm{CO}_{2}$-emitting industries are especially needed in the transition period until new and renewable energy technologies can fully replace technologies based on fossil fuels. Several processes for carbon capture will be developed further, and the current loss of plant efficiency compared with a conventional electrical power plant can be reduced. Storing $\mathrm{CO}_{2}$ is a developing technology, especially in oil fields combined with enhanced oil recovery. High priority should be given to providing a knowledge base for planning and public acceptance.

Low-emission and high-efficiency combustion processes comprise a key element in meeting the climate objectives. Improving conventional processes by new materials and technologies and new combustion processes have priority, including the use of combined fossil fuel, biomass and waste as an energy source.

\section{Energy efficiency}

The building sector has strong potential for energy conservation, which is economically attractive in most cases. The technology is available, and the challenge is to combine technical innovation with economic optimization and to create incentives to deploy the solutions.
This applies to both new buildings, which are the main focus in rapidly developing economies, and for retrofitting the existing building stock. The challenge is further to bring the individual technologies into use through an integrated design process that reconciles energy conservation, construction requirements, architecture and end-user demands. Most existing houses will also be in use in 2050, and thus long-term planning is needed both for individual homeowners and for energy system planners.

Transport relies overwhelmingly on fossil fuels today. Worldwide, transport is linked to economic growth and is expected to increase in the long term. Each subsector has considerable potential to reduce greenhouse-gas emissions. In intercontinental marine transport, $\mathrm{CO}_{2}$ emissions can potentially be reduced by $40 \%$ by improving operational management and implementing technical improvements such as propellers and hull friction. In international passenger air transport, much can be achieved be reducing flight speed, optimizing air traffic and introducing synthetic fuels based on renewable energy. In private car transport, the main solutions are related to the links with the overall energy systems by electrifying the cars or using synthetic fuels based on renewable energy. In addition, improving efficiency can contribute significantly. The main solutions for roadbased freight transport are improving efficiency, operational measures and switching to fuels based on renewable energy.

\section{B. Climate-proofing societal planning and management}

Climate change is expected to occur at a scale that adversely affects social welfare and the economy in most regions, and societies therefore need to adapt to change. Since climate change is expected to occur gradually and clearly within the long lifetime duration of key infrastructure, such as urban design, water cycle management and transport infrastructure, a new basis for management and planning must be implemented. The planning tools, codes and practices of the last century were based on hindcasting using statistical data covering relatively stable basic climate conditions. This is no longer the case, and risk management analysis serving as a basis for policy decisions on infrastructure planning, food supply and health aspects need to be dynamic in the sense that risk management models and planning tools include recurrently updated climate change forecasts. Three robust conclusions related to climate-proofing can be drawn from the workshops. 


\section{Improving the ability to predict climate regimes} First, we recommend strong efforts to improve the ability to predict regional climate change, especially basic climate parameters such as temperature and water cycle pattern. This will provide key input to dynamic planning tools. The work will require a space-based surveillance and monitoring system and coordinated scientific effort to describe the key processes and to develop usable prediction tools.

\section{Climate change effects and the carbon cycle}

Enhanced $\mathrm{CO}_{2}$ levels, climate-induced changes in biological production, human population growth and associated demographic changes will affect the global carbon cycle. There is considerable uncertainty, but changes in marine and terrestrial ecosystems and in the balance between food production, forests and natural ecosystems will alter the fluxes within the global carbon cycle. Priority should be given to studying and modeling key relationships and to making such knowledge an integral part of planning of food production, forestry, urbanization and biological management in broad terms.

\section{Infrastructure and other societal planning and management}

The planning of urban development and infrastructure design will be challenged by a gradually changing climate. High priority should be given to developing knowledge and tools for dynamic risk assessment, especially for infrastructure. Other important sectors of society will also need to consider climate adaptation. In general, climate change will be accompanied by other changes such as demographic change and new trade and travel patterns. This will affect animal husbandry and food safety aspects, and new risk patterns must be described and modeled.

\section{Partnerships for innovation and deployment}

The climate policy objectives are to reverse the direction of the greenhouse-gas emission curve as soon as possible, to halve emissions in 2050 and to implement a global carbon-neutral economy by the end of the century. Given that very few of the necessary tools and processes are commercially mature in 2009 , all effort should be exerted to improve the innovative capacity of society.

\section{Global partnerships for the development and deployment of key technologies}

Several key technologies have been identified. The actual configuration of technologies that is most relevant and cost-efficient for a specific country or region differs and needs to be tailored to the purpose and the resources available. However, the technologies will be similar, and there will be vast synergy in joint development programs. Such programs should be viewed in a global context, since the current competency clusters in science and industry often develop in parallel in various parts of the world.

\section{Strong focus on basic technology and science}

Several challenges in the second phase after 2050 will be very difficult to overcome with current technology, and a technology regime shift or a technological breakthrough is needed. Such problems include energy storage and energy transmission.

\section{Systematic and enhanced efforts in innovation and entrepreneurship}

Innovation and entrepreneurship should be supported to ensure that scientific advances are rapidly disseminated and deployed in the economy. A systemic and systematic approach to innovation should be applied across companies and across university-industry collaboration and provides tools for systematically reducing uncertainty in high-risk and high-reward innovation projects.

\section{Develop capacity for assessing technology and for providing scientific advice}

The capacity to develop and transfer knowledge between science, industry and public authorities should be promoted by strategic alliances and focus on the efficient flow of information. The scientific community will develop insight and models that consider the strong interdependence between sectors and are based on current and evolving technologies. Close collaboration and information flow between industry, public authorities and science is mandatory.

\section{Capacity-building}

Competencies need to be developed at all levels. Education in both science and implementation must be strengthened to increase the capacity and adapt to the needs, especially concerning new integrated technologies and systemic orientation. Personnel should be aware of and qualified for intersectoral and interdisciplinary collaboration. Public awareness of solutions, rules and incentives should be enhanced to promote rapid deployment and innovative capacity. 


\section{Setting the stage: the climate change challenge}

The Fourth Assessment Report of the Intergovernmental Panel on Climate Change (IPCC) concluded that

"Warming of the climate system is unequivocal, as is now evident from observations of increases in global average air and ocean temperatures, widespread melting of snow and ice and rising global average sea level" (IPCC, Synthesis report, 2007, page 1). Based on this conclusion, the IPCC suggested that avoiding dangerous anthropo- genic influence on climate change requires stabilizing the global atmospheric greenhouse-gas concentrations over the next century.

The IPCC report assesses the effects of different average global temperature increases on ecosystems, water, biodiversity, health, agriculture and other human and natural systems, and it concluded that increases

Fig. 1. Stabilization pathways and global greenhouse-gas emissions corresponding to alternative global warming levels, 2000-2100. Green is the pathway equivalent to a $2^{\circ} \mathrm{C}$ rise in global temperature. SRES: based on the IPCC Special report on emissions scenarios. eq: equivalents. Source: Metz B et al, eds. Climate change 2007: mitigation of climate change. Geneva, IPCC, 2007.

\section{World $\mathrm{CO}_{2}$ emissions (GtCO2/yr)}

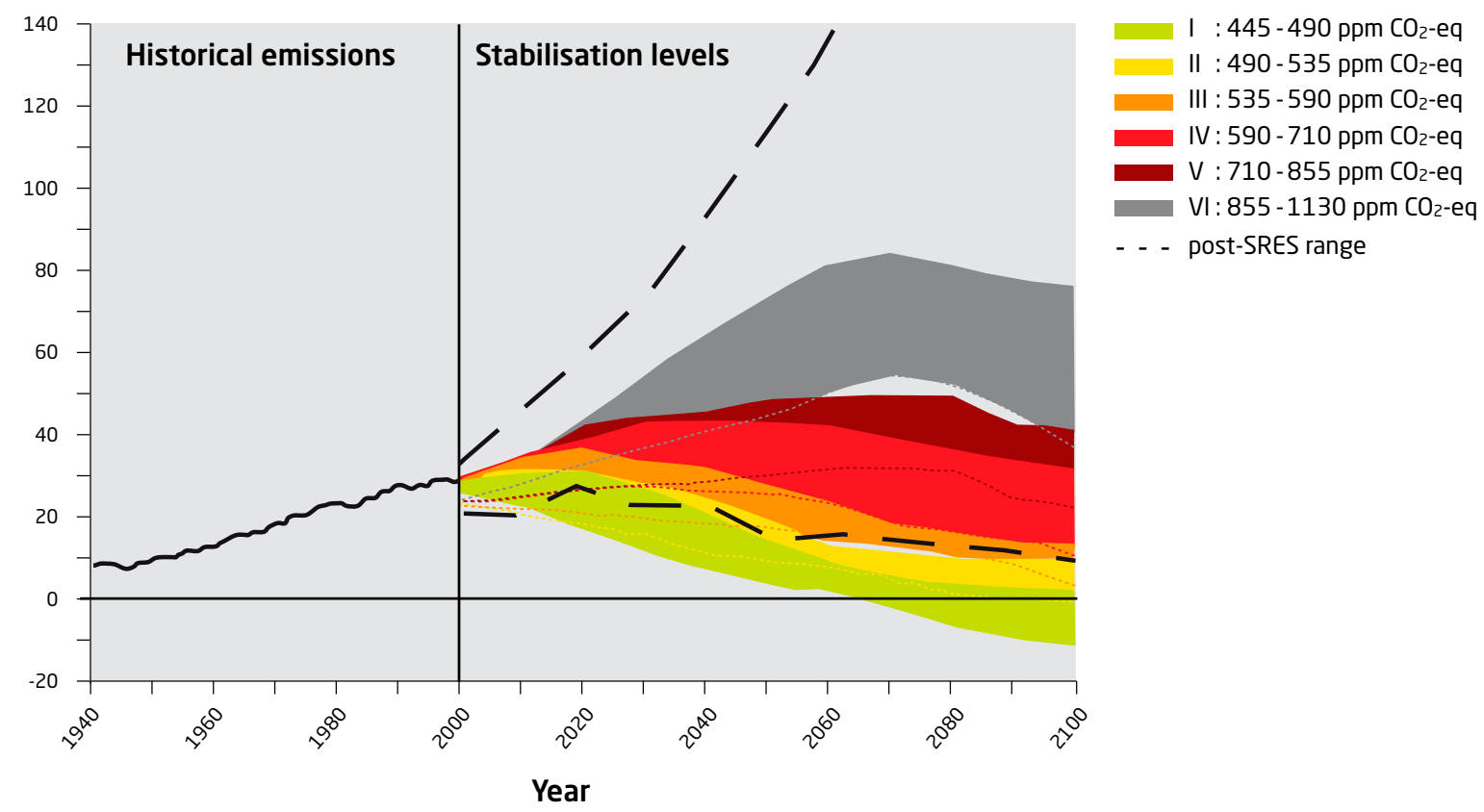


exceeding $2^{\circ} \mathrm{C}$ more than preindustrial levels could impose great risks. Achieving such a stabilization of temperature requires rapid and very large reductions in greenhouse-gas emissions; these reductions have to accompany climate change adaptation as a response to the climate change effects that are already inherent in the elevated atmospheric greenhouse-gas concentrations. Fig. 1 from the Synthesis report of the IPCC Fourth Assessment Report illustrates the rapid reductions in greenhouse-gas emissions needed to meet the low stabilization targets.

Limiting climate change requires rapidly breaking the upward trend in global $\mathrm{CO}_{2}$ emissions. This can be done by improving energy technologies and systems that can rapidly affect the market. The short time requires utilizing all technical potential to reduce $\mathrm{CO}_{2}$ emissions. Long-term technology solutions are also needed that can radically change energy systems in 20-40 years to halve $\mathrm{CO}_{2}$ emissions compared with present levels. It requires that governments, the private sector and science and technology jointly play a leading role in this rapid transition to clean technology. At the same time, options for adapting to climate change have to be planned and implemented to cope with the emerging effects of climate change.

The IPCC Fourth Assessment Report concludes that climate change mitigation and adaptation should be integrated into economic policies. Climate change is closely linked to economic development through a two-way relationship. Economic activities generate greenhouse-gas emissions, but climate change seriously threatens the economic, social and environmental dimensions of sustainable development. This indicates the need for green economic growth patterns that emphasize clean technologies and environmentally sound production processes and lifestyles.

The current global recession has initiated a political and technical debate about how policies and investments that decarbonize society can support future economic growth and prosperity. The idea is that current economic stabilization policies can be combined with environmental policy objectives such that new investment is carried out and employment is created simultaneously with policy objectives related to climate change. Current examples of such efforts include renewable energy, electric and hybrid cars, cleaner coal-combustion processes and bioenergy. Thus, economic policies and climate change mitigation can develop in parallel.

Rapid development and deployment of technology can reduce emissions without hampering economic growth and social welfare. The potential for reducing emissions through mitigation differs between sectors both in terms of the effects of reduction, economic feasibility and time due to the level of maturity of the technologies.

The links between climate change and economic development are multidimensional, and coordinated policy efforts therefore need to be carried out in many sectors. Socioeconomic development and technological change drive greenhouse-gas emissions, and production and consumption patterns are major drivers. The increasing atmospheric greenhouse-gas concentrations influence ecosystems, water, food, health and human living conditions, and various adaptation measures are needed. Nonlinear processes may play an increasing role with larger temperature increases, causing more rapid or abrupt changes in biogeochemical fluxes with consequences for the rate of climate change.

One major global challenge is that a huge portfolio of climate-benign technologies must be implemented in existing and newly established energy systems within the next $10-20$ years. Although many climate-benign technologies are ready for the market now, a special effort is required to ensure that financing and other implementation requirements are in place. Part of the effort needed here is to facilitate worldwide cooperation framed by a new global climate change agreement.

Achieving the necessary but also very ambitious technology transition implies that DTU and similar institutions around the world can play an important role through research on, development on and deployment of climate-benign technologies. Nevertheless, many attractive technologies that can be part of the solution are available on the market today, and implementation efforts and partnerships across the business sector and scientists can speed up this process.

These challenges call for an effort to accelerate the development and deployment of technology. The DTU Climate Changes Technologies workshops discussed technology tracks, identified bottlenecks for rapid development and deployment and recommended solutions. The workshop covered climate change mitigation, climate change adaptation and the need to monitor the effects of climate change. Section 3 of this report provides detailed information about workshop conclusions and recommendations on climate mitigation in relation to energy supply. Section 4 deals with climate change adaptation and impact assessment and gives recommendation on several specific key sectors. The policy target for a maximum global temperature of $2^{\circ} \mathrm{C}$ sets a tight time constraint on reducing greenhouse-gas emissions. Section 5 addresses the need to improve the innovative capacity of society in order to meet the time requirements. 



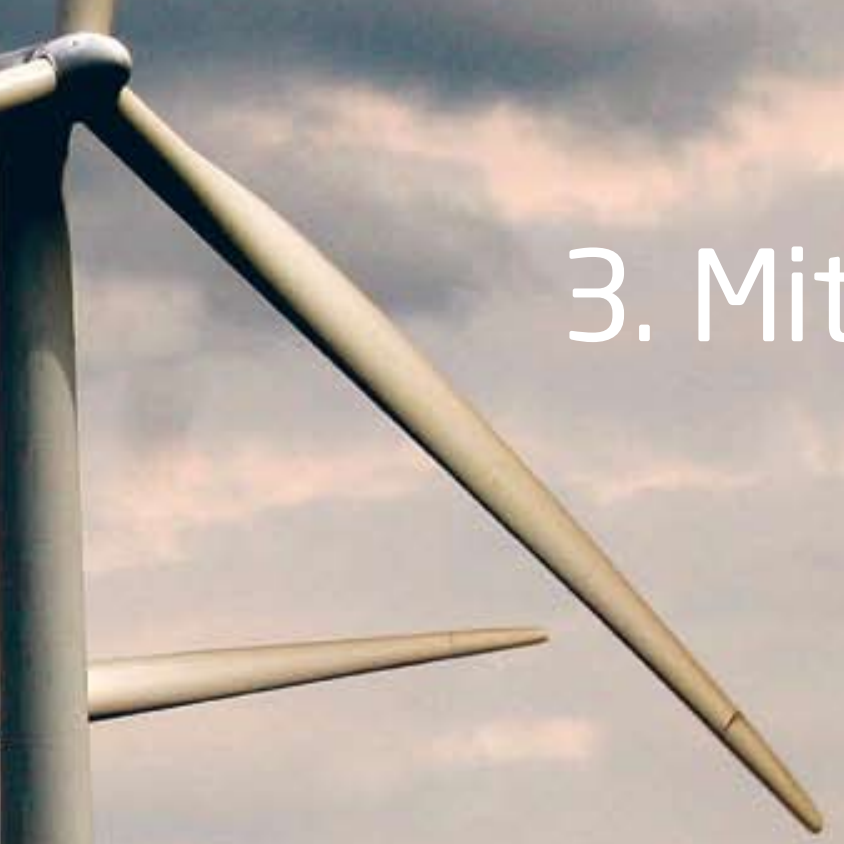




\section{Mitigation}

Today's energy systems have been developed over several decades, and this is reflected in the structure of the present energy systems, which have been developed to be largely based on fossil fuels with energy supply from centralized electrical power plants and, secondarily, on local energy supply.

A prerequisite for limiting climate change is finding solutions on the local, regional and global levels that can lead to $\mathrm{CO}_{2}$ emissions peaking before 2020 and subsequently declining to less than $50 \%$ in 2050 globally and even more in industrialized countries. Long-term technology solutions are also strongly needed that can radically change the world to $\mathrm{CO}_{2}$-free energy supply and use in industrialized countries by the end of the century. This can be done by combining:

- developing new energy system infrastructure that can rapidly affect the market;

- deploying new sustainable energy technologies with a focus on renewable energy; and

- improving efficiency both in supply and end-use.

The short time requires utilizing all technical potential to reduce $\mathrm{CO}_{2}$ emissions.

Today the world largely depends on fossil fuel, amounting to $80 \%$ of the global energy supply, $6 \%$ from nuclear power, $10 \%$ from traditional biomass and $2 \%$ from hydroelectric power, leaving less than $2 \%$ to other sources, including new renewable sources such as wind and solar. The new renewable energy sources are increasing rapidly as Table 1 illustrates.

Supplies of oil and natural gas will dwindle in the coming decades, whereas coal is an abundant and geographically widespread fuel, leading to a high security of supply and more stable prices. For these reasons, interest is significant in continuing to use coal as fuel for generating heat, electrical power and process energy for many years to come.
Wind energy has doubled the global capacity every 3 years in the past 25 years, and today the generation capacity accounts for $1.3 \%$ of global electricity consumption. One percent of the global wind energy capacity is installed offshore.

Solar energy might become a major component of future sustainable energy supply in the form of solar heating and cooling, photovoltaics or concentrating solar power. Solar thermal power might cover up to $50 \%$ of the heating and cooling demand in Europe by 2050. Similar potential is found for electricity generation for cities in Europe. However, these estimates are very uncertain. The main challenge for the solar energy industry is to reduce production costs.

Bioenergy can be produced from a variety of feedstocks and waste, and the growth potential largely depends on the ability to develop new feed-stocks and more efficiently convert of existing sources and waste flows into energy. Biomass can be stored both in its original form and as preprocessed materials with a higher energy density.

Hence, although renewable energy started with a small share of the global energy supply, it has been growing rapidly in the past 5 years. This has partly been policy driven but also reflects increasing private-sector interest in investing in renewable energy as a future profitable business area. Wind remains the dominant source, but both solar photovoltaics and water heating are expanding very rapidly, and production facilities are emerging in several developing countries to facilitate continued expansion in the rapid growing economies. At the global level, all known sustainable energy technologies must be used to control $\mathrm{CO}_{2}$ emissions. However, the solutions are quite different in various regions. 
Table 1. Total global new renewable energy installed, 2006-2008

\begin{tabular}{|l|c|c|c|}
\hline & 2006 & 2007 & 2008 \\
\hline Wind power capacity (gigawatts (GW)) & 74 & 94 & 121 \\
\hline Grid-connected solar photovoltaic capacity (GW) & 5.1 & 7.5 & 13.0 \\
\hline Solar hot water (annual) GW thermal & 105 & 126 & 145 \\
\hline
\end{tabular}

Source: Renewables: global status report - 2009 update. Paris, Renewable Energy Policy Network for the 21st Century - REN21 Secretariat, 2009.

The energy systems of the future have to undergo fundamental changes in structure to accommodate the increasing supply of fluctuating renewable energy. The future changes in energy systems require a technological revolution through outstanding collaboration between authorities, scientists and industry. Rapid development and deployment of technology can reduce emissions without hampering economic growth and welfare. The potential for reducing emissions through mitigation differs between sectors both in terms of the effects of the reduction, economic feasibility and time due to the maturity level of the technologies.

The main challenge is to get the attractive mitigation options diffused and utilized on a large scale worldwide. The task of utilizing the mitigation potential is immense and requires not only great investment in research, development, demonstration and deployment but just as much adequate policies and removing barriers to implementation. Further, establishing long-term stable global policies is important, including environmental, financial, infrastructural, research and educational issues. 


\subsection{Recommendations on mitigation}

Overall energy systems must be optimized as a whole. This will enable a close link between energy supply, energy systems and end-use (including buildings and the transport sector). Buildings must be part of overall energy systems, because the future low-energy buildings will both consume and produce energy. Further, the transport sector has to be integrated into energy systems to increase the share of fuels based on renewable energy. These future energy systems will increasingly need energy storage capability.

Developing energy systems of the future requires fundamental changes in the structure of electrical power systems caused by the rapidly increasing amount of fluctuating renewable energy that is being connected to the systems but also by connecting new types of production and consumption technologies. One such change is a general increase in distributed generation units of a smaller scale than traditional thermal power plants. This development can include the low-voltage connection of micro-combined heating and power plants in individual households in the future. Parallel with this development, increased use of information and communication technologies is needed. Communication capability is rapidly increasing while becoming less expensive. This enables a system permitting bidirectional communication with end-users and is thus one of the most important enabling technologies for future electrical power systems. This will enable the close link between supply, systems and end-use, including buildings and the transport sector.

Numerous sustainable energy supply technologies are available today, and much can be achieved with these technologies in the short term, but the new renewable energy technologies such as solar power, wind and second-generation biofuels might have high annual growth rates but started from low levels. Nuclear fission energy today supplies $6 \%$ of the world's energy and $15 \%$ of global electricity production as a $\mathrm{CO}_{2}$-free energy source. A total of 440 nuclear reactors are operating in 31 countries. The potential is great in particular if not only uranium but also thorium are used as fuel sources, but forecasting growth rates in the years ahead is difficult for political and public acceptance reasons.

Wind energy is the dominant new renewable energy source today, and the global capacity has doubled every 3 years in the past 25 years. The generation capacity of 121 GW accounts for $1.3 \%$ of global electricity consumption. A target for 2050 might be $25 \%$, as suggested to the International Energy Agency in 2008. The development of wind energy primarily focuses on dedicated offshore wind farm solutions including support structure. Reaching this target requires optimizing the technology related to the turbine, the infrastructure and energy system integration. Achievements in off shore technology will be transfered to land-based systems. Key focus areas are:

- turbine efficiency and grid connections;

- reduced costs and improved cluster collaboration; and

- concerted action towards area planning, construction and grid connections.

Solar energy may become a major component of future sustainable energy supply in the form of solar thermal heating, photovoltaics and concentrating solar power. Targets for deploying solar energy are continually increasing, and it is too early to definitively determine how much energy solar will supply globally. Theoretically, solar energy is the largest renewable energy source. Solar cells, solar thermal heating systems and concentrating solar power plants are well proven and mature technologies that have been installed at an unprecedented pace in the past few years. Solar thermal power might cover up to $50 \%$ of the heating and cooling demand in Europe by 2050. Electricity generation for cities in Europe has similar potential. These estimates are subject to major uncertainty. The main challenge for industry is to reduce production costs. Key focus areas are:

- building codes and energy plans to provide incentives

for solar thermal heating;

- improved efficiency in photovoltaics; 
- reducing costs and market deployment (incentives); and - establishing a European supergrid linked to northern Africa.

Bioenergy can be produced from a variety of feedstocks such as waste and biomass produced directly as input for energy production. The limitation is mainly due to competition in land use for food production and the challenge is to develop new feed-stocks and more efficiently convert of existing sources and waste flows into energy. Biomass might be used as fuel in power plants or converted to liquid fuel in the form of bioethanol or biodiesel for transport. Bioethanol might be one of the only options for alternative fuel for the air transport sector, and what is left could be used for heavy road transport. Key focus areas are:

- highly efficient decentralized biorefinery plants; and - new feed stocks, such as microalgae for biodiesel production.

Energy storage facilities are of paramount importance for leveling out the mismatching fluctuation in supply and demand in future energy systems with a high share of intermittent renewable energy sources. This includes both centralized electricity and heat storage facilities and small mobile batteries for transport. Candidates for these technologies or fuels already exist - such as batteries, hydrogen and fuel cells - but characteristically they all need to be developed technically and economically to compete in the market. The main challenges are increasing energy density and reducing losses and costs. The key focus area is:

- potential technologies for large-scale electricity storage over a period of months: pumped storage hydroelectricity, compressed air energy storage or production of hydrogen.

Combustion efficiency in terms of low emissions per power unit generated is a key element in meeting the climate objectives. Technology pathways to continue improving efficiency have been identified, ranging from improving conventional processes by using new materials and technologies to new combustion processes. Improvements include using combined fossil fuel, biomass and waste as an energy source. Key focus areas are:

- improved power plant technology (materials) and new combustion processes; and

- large-scale test and demonstration facilities.

Carbon capture and storage in power plants and $\mathrm{CO}_{2}$-emitting industries are especially needed in the transition period until new and renewable energy technologies can fully replace technologies based on fossil fuels. Several processes for carbon capture are being considered: post-combustion and pre-combustion capture and oxyfuel combustion. All these technologies reduce the current efficiency of a conventional power plant by about $8-10$ percentage points. Storing $\mathrm{CO}_{2}$ is a rapidly developing technology, especially storing $\mathrm{CO}_{2}$ in oil fields combined with enhanced oil recovery.

The existing building stock has great potential for conserving energy, and this conservation is largely economically attractive. The technology is available, and the challenge is to combine technical innovation with economic optimization and to create incentives to deploy the solutions. Public incentives are needed. Low-energy houses (energy consumption less than $10 \%$ of that in existing buildings) can be built today for $5-10 \%$ more than conventional houses. The challenge is to bring the individual technologies into use through an integrated design process that reconciles energy conservation, construction requirements, architecture and end-user demands. Most existing houses will also be in use in 2050, and long-term planning is thus needed for both the individual homeowner and energy system planners. The main drivers for conserving energy in the building sector are regulation and incentives.

Transport is a challenge, as it relies solely on fossil fuels today. Worldwide transport activities will continue to grow rapidly in the foreseeable future. In intercontinental marine transport, $\mathrm{CO}_{2}$ emissions can be reduced by about $10-15 \%$ for each of the following measures: operational, such as slow steaming; technical, such as improved propellers, hull forms or diesel engines; and market-based measures, such as a global emission-trading scheme. In international passenger air transport, much can be achieved by reducing flight speed, optimizing air traffic and introducing synthetic fuels based on renewable energy sources. In private car transport, the main solutions are related to linking with the overall energy systems by electrifying cars or using synthetic fuels based on renewable energy sources. In addition, improving efficiency can contribute significantly. The main solutions for road-based freight transport are improving efficiency, operational measures and switching to fuels based on renewable energy sources. Government strategies, planning and incentives must regulate the overall balance between the various transport opportunities.

Research is needed on new energy technologies to be introduced into energy systems beyond 2050 when greenhouse-gas emissions have to be reduced drastically compared with today. One option would be fusion energy, but the time horizon is very long, as the first commercial power plant is not expected to go on line until after 2050 based on the research and development planned today. Another long-term option would be to move towards hydrogen-based energy systems using fuel cells powered by hydrogen produced from renewable or nuclear sources. 


\section{Mitigation}

\subsection{A Intelligent energy systems}
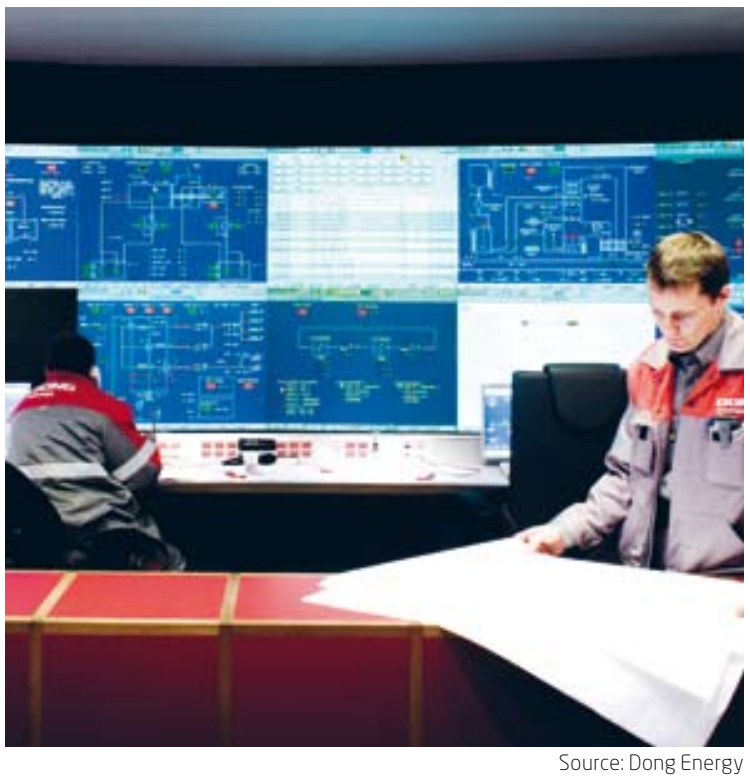

\section{Introduction}

Today's energy systems are the result of decisions taken over several decades. This long-term development is reflected in the structure of energy systems, which in most cases has been developed according to basic engineering requirements: energy is produced to fulfill the needs of energy consumers. However, a new supply structure based on variable energy resources such as wind power will require much more flexible energy systems, including flexible energy consumers. The structure of electrical power systems is currently being changed fundamentally, caused partly by the rapidly increasing amount of fluctuating renewable energy being connected to the systems but also by the connection of new types of production and consumption technologies. One such change is a general increase in distributed generation units of a smaller scale than the traditional thermal power plants. In the future, this can include the low-voltage connection of micro-combined heating and power plants in individual households. Parallel with this, the use of information and communication technology is increasing. Communication capability is rapidly increasing and the cost is declining. This enables systems that permits bidirectional communication with end-users and is thus one of the most important enabling technologies for future power systems.

\section{Challenges and solutions}

Within the energy sector, energy security and climate change are the two overriding priorities, as described in Chapter 3 . This is especially true for industrialized countries and the more affluent developing countries, whereas many other developing countries still face basic energy development constraints that give quite a different meaning to the concept of energy security.

Denmark can change its energy systems to rely mainly on renewable energy and reduce $\mathrm{CO}_{2}$ emissions by $50 \%$ before 2050 compared with the 2008 emission level. The great challenge lies in the energy systems themselves, as they are the prerequisite for the interaction between various supply technologies and end use.

Denmark can become independent of fossil fuels in the long term by improving efficiency in all sectors. At the same time, the share of renewable energy must be increased, with more wind energy and increased use of biomass. Such radical transformation of energy systems takes years or even decades and requires long-term targets; one reason is the long lifetime of supply technologies.

At the global level, all known sustainable energy technologies must be used to control $\mathrm{CO}_{2}$ emissions. However, the solutions differ considerably by region. In countries with rapidly growing developing economies such as China and India, the sensible step is expanding the modern highly efficient technologies, but this requires extensive cooperation with countries that are forerunners 
in developing sustainable energy systems. The least developed countries need to provide modern clean energy and electricity to everyone. Here the high-income countries should help transfer clean energy technologies, based on both fossil fuels and renewable energy.

\section{Implementation issues}

Transforming current energy systems into the intelligent energy systems of the future requires the following.

- Intelligent energy systems that deliver electricity from suppliers to consumers using information and communication technology to save energy, reduce costs and increase reliability should be promoted to the maximum extent. Electric cars should be integrated into energy systems to the maximum possible extent to link energy systems and the transport sector.

- An interconnected intelligent electrical power grid is needed that is integrated at the European level and can accommodate a higher proportion of renewable energy.

- A strong, independent pan-European transmission system operator is needed. Reinforcements are needed at both the national and European scales. An offshore electrical grid is needed.

Peaking $\mathrm{CO}_{2}$ emissions within the next $15-20$ years requires that energy supply and use be sustainable. This requires the following.

- The maximum amount of electricity needs to be generated based on technologies without greenhousegas impact: biomass, wind, solar and nuclear in countries with experience in this technology. Conventional power plants need to be developed to use the best available technology and introduce integrated gasification combined cycle power plants integrated with carbon capture and storage.

- Much can be achieved with known technologies in the short term, but research is needed into new energy technologies and systems to be introduced beyond 2050 .

- Carbon capture and storage are required in electrical power plants and energy-consuming industry until fossil fuels can be phased out, but the costs have to be reduced.

Policy and incentives are urgently needed.

- Strong incentives need to be introduced for changing consumers' behavior to optimally exploit renewable energy and energy conservation. Demand-response options should be introduced for all consumers. This may be done by changing taxation systems to provide the appropriate incentives.

- Long-term targets for renewable energy deployment and stable energy policies are needed to reduce uncertainty for investors. 


\section{Mitigation}

\subsection{B Sustainable energy: MI}

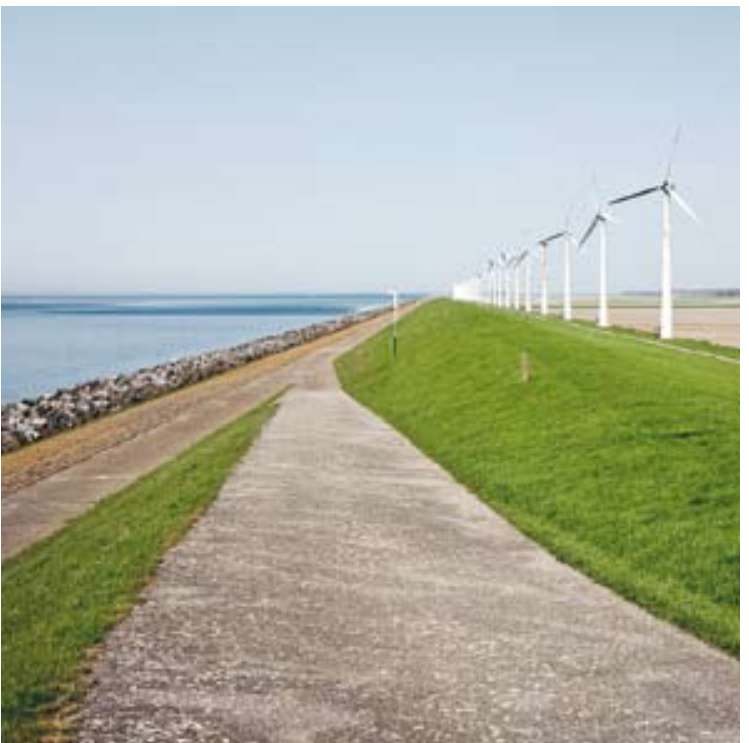

Wind energy

\section{Introduction}

Global wind energy capacity has doubled every 3 years in the past 25 years. The current generation capacity of 121 GW accounts for $1.3 \%$ of global electricity consumption. One percent of the global wind energy capacity is installed offshore.

Future developments for wind power as described in the advanced scenario of the 2008 report by the Global Wind Energy Council (GWEC) and the German Aerospace Center (DLR) and in the 2008 report by the Risø DTU National Laboratory for Sustainable Energy to the International Energy Agency suggest that global wind power penetration can be $25 \%$ by 2050 . These scenarios are based on growth rates of $27 \%$ in 2008 , declining to $22 \%$ in $2010,12 \%$ by 2020 and $5 \%$ by 2030 . Targets of this order are realistic, and the available resource will not be the limiting factor. Thus, global electricity consumption corresponds to that generated by a wind farm area of 1000 $\mathrm{km}$ by $1000 \mathrm{~km}$. Hence, the long-term planning should be based on these growth rates.

The huge potential, the rapid development of the technology and the impressive industrial growth justify the perception that the role of wind energy is changing to becoming the future backbone of a secure global energy supply.

\section{Challenges and solutions}

This vision requires addressing the following issues.

- Technology needs to be optimized, including the turbine, the infrastructure and the integration of energy systems.

- Various subsectors such as wind turbine manufacturers and offshore operators should be more closely integrated.

- A long-term stable global policy needs to be established including environmental, financial, infrastructural, research and educational issues.

- Synergy between wind energy, other electrical power supplies and load control needs to be exploited to obtain integrated, intelligent electrical power systems.

The most important technological research challenges must consider the distinct differences between offshore and onshore technology issues, but applications remain equally important. Hence, offshore applications are the driving force of long-term research and larger turbines, but the results are probably very useful for improving small and medium-sized turbines. Further, the future perspectives and wind energy investment justify a corresponding intensified public-private research and development effort to reduce costs and risks. 
Thus, research must at least address the following challenges.

- Scaling up, improving reliability and reducing costs over lifetime are the key objectives while improving and developing new technological solutions for future large-scale wind energy applications.

- Mechanisms need to be improved to better incorporate the industry's research and development needs into academic and public research and development bodies, and operational data from the industry need to be fed back to research and development to improve operational performance.

- Dedicated offshore wind farm solutions need to be developed, comprising dedicated wind turbine concepts, advanced support structure, power system technologies and transmission systems.

\section{Implementation issues}

These challenges have been discussed in the European Wind Energy Technology Platform during the past 2 years, with the Strategic Research Agenda and Market Deployment Strategy published in fall 2008 as the result. A central point of the Agenda is the need for implementation in a public-private partnership between universities, research institutes and industry, including manufacturers, electrical power companies and transmission system operators as well as implementation in a national and European partnership.

Long-term national and regional planning for wind power with binding targets and commitments is urgently needed, including agreements to facilitate the initiation of the necessary infrastructure investment and to harmonize regulation and permit procedures. Further, political incentives are needed to coordinate and initiate research activities that are based on technology needs and addressed by industry and public research.

It has been proposed that governments co-finance large-scale pilot plants to reduce the risks for private investors and ensure that systematic monitoring and evaluation programs are implemented to stimulate learning processes and to ensure that costs are reduced through improved efficiency. Another suggestion is creating a global think-tank that addresses strategic studies, international offshore policy and needs for databanks. Finally, universal standards are needed for education, dedicated training courses and adapting university curricula.

\section{Solar energy}

\section{Introduction}

Solar energy may become a major component of future sustainable energy supply in the form of solar thermal heating, photovoltaics and concentrating solar power. Targets for deploying solar energy are continually increasing, and it is too early to definitively state how much energy solar systems will supply globally. Theoretically, solar energy is the largest renewable energy source. The Earth receives more energy from the sun in just 1 hour than humanity uses in a whole year. Solar cells, solar thermal heating systems and concentrating solar power plants are well-proven and mature technologies that have been installed at an unprecedented pace in the past few years.

A continuing increase in the installation rate is strongly correlated with declining production costs. This reduction is still needed to make photovoltaics in particular and, to a lesser degree, solar thermal heating and concentrating solar power cost efficient and to make the price of energy produced by these technologies similar to other sources of electrical power, heating and cooling.

Various industry segments, research institutions and public bodies such as the European Technology Platforms have laid plans for incrementally improving the technology, scaling up capacity and deployment scenarios. These plans target the need to reduce production costs and are the background for the ambitious targets described below.

Solar thermal heating and photovoltaic technologies include both centralized and distributed generation of energy and offer a geographical spread of generation over most of the industrialized world. Concentrating solar power targets power plants located in the sunniest regions of the world. The visions of the solar energy sector call for massive deployment of both centralized power plants and distributed power generation: building integrated heating and photovoltaic panels.

This vision constitutes a paradigm shift in energy supply. It requires adopting control and storage technologies that allow the harvested energy to be utilized. Fulfilling the vision requires planning, and starting now, deployment on a large scale, and the industry must strive to reduce production costs while building up production capacity. Globally, a capacity of $145 \mathrm{GW}$ of thermal equivalent (GWth) of solar thermal heating was installed by 2008; 13 GW grid-connected and approximately $14 \mathrm{GW}$ total photovoltaic electric capacity (GWel) was installed by 2008; and about $1 \mathrm{GWel}$ of concentrating solar power by 2008. The solar thermal heating market has grown by at least $30 \%$ annually in recent years. The photovoltaics market increased by $110 \%$ from 2007 to 2008 , and several new concentrating solar power plants are under construction. 
The DTU Workshop on Sustainable Energy reviewed the question of how ambitiously solar thermal energy and photovoltaics can contribute to global energy needs.

\section{Challenges and solutions}

The immediate challenge is to orchestrate combined progress including:

- deploying at rates that vastly increase the installed capacity, with the current increase being more than $30 \%$ annually for all solar technologies;

- accelerating the reduction of costs by industry as the production capacity is increased, with the reduction corresponding to a learning rate of $15-20 \%$; and - creating a stable market.

In the medium term, technological progress in new generations of photovoltaics and efficient thermal storage will enable ultra-low-cost solar cells and much more widespread use of solar thermal heating and cooling. For concentrating solar power, new collector technologies allowing higher working temperatures will increase efficiency and thermal storage will enable power generation to be spread over the whole day.

Further, in the medium term, up to 10 million professionals need to be educated and trained to fulfill the vision for solar energy penetration.

Incremental technological development and innovation in industry can meet the short-term technical challenges. Public incentive mechanisms have been extremely important for the solar energy market. Feed-in tariffs for photovoltaics have been the most successful tool for establishing a market, and as a result, a rapidly growing industry. The vision reports and programs describe a close public and industrial partnership to achieve the vision. Perhaps the most important messages to convey from the vision are the following.

- Solar thermal heating systems are already cost-efficient in many cases, and creating awareness of the technical potential is a major challenge.

- Within the next 10 years, photovoltaics will deliver electrical power at the same price as residential electricity prices (grid parity) in nearly all parts of the industrialized world, and incentives will no longer be needed.

- Major companies are joining together to push the concentrating solar power technology towards being an important component of Europe's electricity supply.
The report from the DTU Workshop on Sustainable Energy provides many details. The challenge at this Workshop was to review how ambitiously solar thermal energy and photovoltaics can contribute to global energy needs. The Workshop responded as follows.

1) Solar thermal energy should cover at least $50 \%$ of the heating and cooling demand in Europe by 2050. The major challenges are to create awareness and knowledge about the high potential for solar thermal energy systems and to improve the cost-performance ratio of the solar thermal systems marketed. Focus areas for research and development are developing advanced heat storage technology with a strongly increased storage capacity compared with storing water and developing solar heating systems with strongly improved cost-efficiency. 2) Solar cities should produce $50 \%$ of the regional - or even national - electricity demand by 2050 . The focus should be on the OECD (Organization for Economic Co-operation and Development) countries towards 2050, Brazil, Russian Federation, India and China towards 2075 and the whole world by 2100 .

A solar city is largely powered by solar energy, especially electricity generated by photovoltaics. In a solar city, photovoltaics is integrated with buildings and deployed on up to $25 \%$ of rooftops and free spaces. The concept of a solar city implies a sustainable society in which energy conservation accompanies building integrated power generation and solar thermal heating and cooling. For photovoltaics, the research and development focus is reducing the production costs of current generations of photovoltaics and developing new generations of photovoltaic technologies.

3) Education in the use of solar energy should be implemented at all levels of society. An estimated 10 million professionals will be needed in various branches of the global supply chain of solar thermal and photovoltaics by 2030 . Hence, there is clearly a pressing need to push for educating technical personnel in universities and technical schools.

\section{Implementation issues}

In general, a public and industrial partnership is needed within research and development, demonstration and market deployment, policy measures and education. The European Commission's Strategic Energy Technology Plan offers one solution, and the proposals by the European Society for Engineers and Industrialists (SEII) and European Energy Research Alliance (EERA) provide detailed examples. 
Distributed generation of solar thermal energy and photovoltaic power generation will compete for the same rooftops, façades and free spaces in cities. This should be considered when solar cities are planned.

Solar thermal heating can become of increasing value as a heat source for established central heating systems.

Widespread use of photovoltaics requires developing a stable electricity grid for a distributed generation system. In particular, deploying concentrating solar power in such an area as the Mediterranean necessitates a well-established transmission system between Europe and northern Africa.

One likely way to optimize the use of photovoltaic systems for distributed power generation is dividing the grid into robust cells in which the fluctuating electricity demand is balanced by the sources and the intermittent power sources and storage sinks complement one another. Demonstration of new technologies develops through a series of larger and larger projects in which industrial partnership is required to meet the market demands and public partnership is required to accelerate research and development and to lower industry's risks in implementing new technology on a large scale.

Harmonizing and adapting standards and regulations will make installing individual solar energy systems easier.

\section{Bioenergy}

\section{Introduction}

Bioenergy can be produced from a variety of feedstocks such as waste and biomass directly produced as input for energy production. The waste products include household waste, animal manure and waste products from the food industry. Residue from agriculture and forestry includes straw and wood chips. Biomass produced directly for energy purposes includes corn, cereals, sugar beets, rapeseed and rapidly growing types of trees such as willow. All these materials constitute a limited resource. This limitation is mainly due to the possible competition in land use for food production and the availability of land. Biomass can be stored both in its original form and as preprocessed materials with a higher energy density. Biologically based energy carriers are plentiful, which makes bioenergy the most flexible sustainable energy form. The potential for bioenergy to mitigate climate change is high but only if this resource is used optimally both in relation to sustainability (effects on the environment and climate) and in relation to the need for specific energy carriers. Liquid biofuels are especially suited for the transport sector. They might be the only sustainable solution for air transport and constitute important solutions for sustainable land and marine transport until other options become feasible.

\section{Challenges and solutions}

Biomass has long been used as a source of energy. The most common form of bioenergy has been and still is burning wood. Dry biomass is generally well suited for combustion in centralized or decentralized units. In addition to wood, straw has been highly used (for example, in Denmark) for co-firing in power plants. However, meeting the increasing demands of these materials is a challenge, and technologies should continually be developed to increase the efficiency of the furnaces.

Alternative technologies to simple combustion are thermal gasification and pyrolysis. In thermal gasification, synthesis gas (syngas) can be produced together with heat. The syngas can be used directly for generating electricity or transformed into various liquid biofuels. The available gasification technologies should be tested in demonstration plants, and the role of biomass in combined energy systems should be optimized. Pyrolysis can produce a crude bio-oil together with biochar. The bio-oil can be used directly in large diesel engines, and the biochar, which is very stable, can be incorporated into the soil, removing carbon from the atmosphere and increasing soil fertility.

Wet biomass such as sewage sludge and manure is most suitable for biogas production. Biogas produced from cattle and pig manure can thus provide substantial energy and help in solving a waste problem. Countries such as Denmark with substantial livestock production have huge potential for increasing energy production from these sources. The biogas can be used directly for heating and as energy for transport after further refining.

Decentralized biorefinery plants should be built and infrastructure for distributing biogas for transport should be established to effectively increase the energy obtained from these sources. Research should focus on including new feedstocks in biogas production, on separating manure into solids and liquids and on managing nitrogen and phosphorous in agricultural systems.

Bioethanol and/or higher alcohols such as butanol should replace an increasing proportion of the gasoline used, with certified reduction in greenhouse gases by at least $80 \%$ compared with gasoline. Research is needed to improve the use of sugars that are not easily fermented (C5 sugars) for alcohol production and other high-value products. 
Biodiesel production from microalgae should be investigated. Microalgae can produce much more biomass per unit area than conventional energy crops. Further, they can be produced in areas not suitable for growing food crops. The production can use nutrients from wastewater and $\mathrm{CO}_{2}$ from flue gas. Microalgae can directly produce fat, which can easily be converted to biodiesel. The main technological challenges are developing growth systems and inexpensive harvesting methods.

\section{Implementation issues}

Increased utilization of bioenergy should be facilitated by regulation and economic incentives, such as reducing excise taxes.

Biogas use should be facilitated by a strategy for increasing the number of biogas plants and on providing economic incentives for increasing biogas use. Spreading untreated manure on agricultural fields should be phased out.

Replacing local natural gas-fired heating with district heating from combined heat and power generation should be promoted.

Compulsory mixing of liquid biofuels (bioethanol/ biobutanol and biodiesel) with fossil fuels should be established, and flexifuel vehicles should be introduced.

Secondary biomass (waste) should be the main source for bioenergy production. Primary biomass should only be used when sufficient attention is paid to all sustainability aspects, such as strategies to promote rural development or reduce poverty. Nutrient-rich residue from bioenergy production should be recycled to maintain soil fertility. Sustainability issues should be in focus in education at all levels. 


\subsection{Energy storage
technologies}

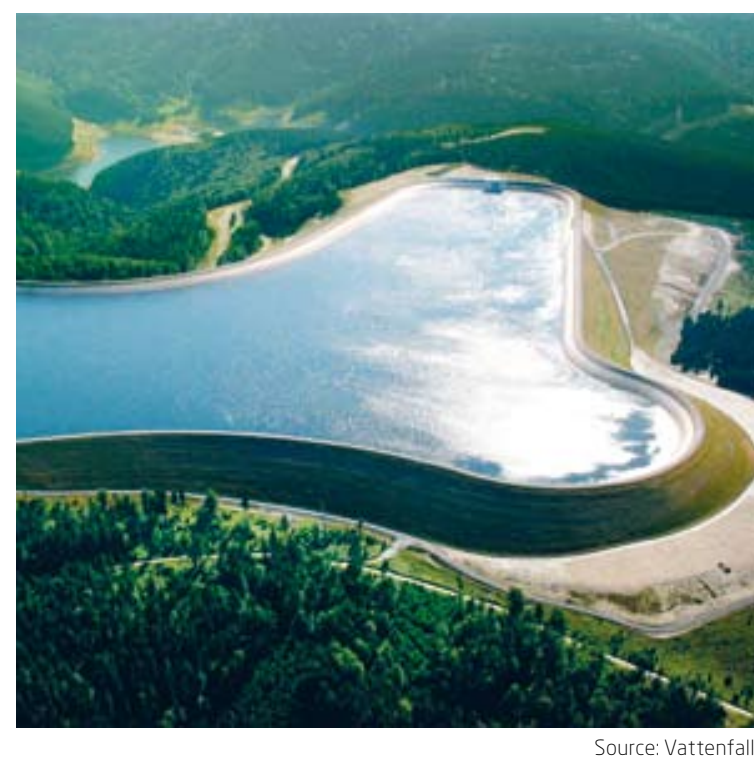

\section{Introduction}

Future sustainable energy systems, based on renewable energy sources, will inevitably need technologies for energy storage. Energy production will not always match the natural demand for energy, and storage facilities must be integrated to level out the mismatching fluctuation in supply and demand. As (simple) examples, the electricity wind turbines generate in many geographical regions varies intensely by season, which may create a need for storing large amounts of electricity for several months. Similarly, the electricity generated by wind does not have a systematic pattern during the day or night, whereas the demand typically varies strongly during 24 hours, requiring facilities capable of storing energy for hours. Further, much of the primary energy in future sustainable energy systems will be generated as electricity from wind turbines, solar cells, wave power or similar technologies. Thus, fossil fuel can no longer be relied on for transport. Other technologies based on new fuels will have to be implemented for marine, land and air transport of passengers and goods. Candidates for these technologies or fuels already exist - such as batteries and hydrogen and fuel cells - but all need to be developed technically and economically to compete in the market.

\section{Target descriptions}

- Facilities sufficient to store excess electricity for months must be developed. Potential technologies for this kind of energy storage are pumped-storage hydroelectricity, compressed air energy storage and large-scale production of hydrogen or hydrogen-rich compounds.

- In energy storage for transport, several technologies and new types of fuel are competing and are still too premature to determine the best ones. However, an ambitious and important target would be developing technology for producing synthetic fuel to yield a price equivalent to the price of oil of about USD 8-16 per GJ. Such a price would allow considerable market introduction of these types of fuels (synthetic fuel means any fuel produced without using minerals).

- A crucial target for batteries for transport is they must fulfill the customers' expectations for using the vehicles. This requirement seems straightforward, but batteries today perform far from satisfactorily in terms of energy capacity (driving distance), durability (charging and discharging patterns) and economy.

- Options for storing heat should be improved. Technologies should be developed that enable - technically and economically - a considerable fraction of heat to be stored, which otherwise dissipates. Introducing such technologies can substantially reduce the demand for conventional heat production. 


\section{Challenges and solutions}

Major challenges for appropriate energy storage technologies are:

- obtaining high energy density and low cost for storage systems;

- reducing the loss of heat in energy conversion processes;

- improving safety, including safety within the vehicles, of energy storage devices; and

- establishing infrastructural support for centralized and decentralized installations for storage of energy. The energy must be transferred between the sites of production, storage and end use. The existing grid as well as other distribution systems (such as for the hydrogen) may not be sufficient to fulfill the requirements.

The scale of the future need for energy storage capacity is difficult to assess, as it depends on many unknown factors. Examples of such factors that may influence the need are the degree to which electricity is exchanged at the regional level and the ability of energy demand to adapt to variation in production. Nevertheless, energy storage will definitely be integrated into fully developed, sustainable energy systems.

\section{Implementation issues}

- Technologies need to be improved by accelerating research and development in collaboration including both industry and research.

- The storage technologies that may be suitable for specific purposes need to be analyzed in detail economically and technically.

- The transport fuels that are appropriate for specific transport applications need to be analyzed in detail.

- The required technologies need to be standardized at an early stage of industrial development. 


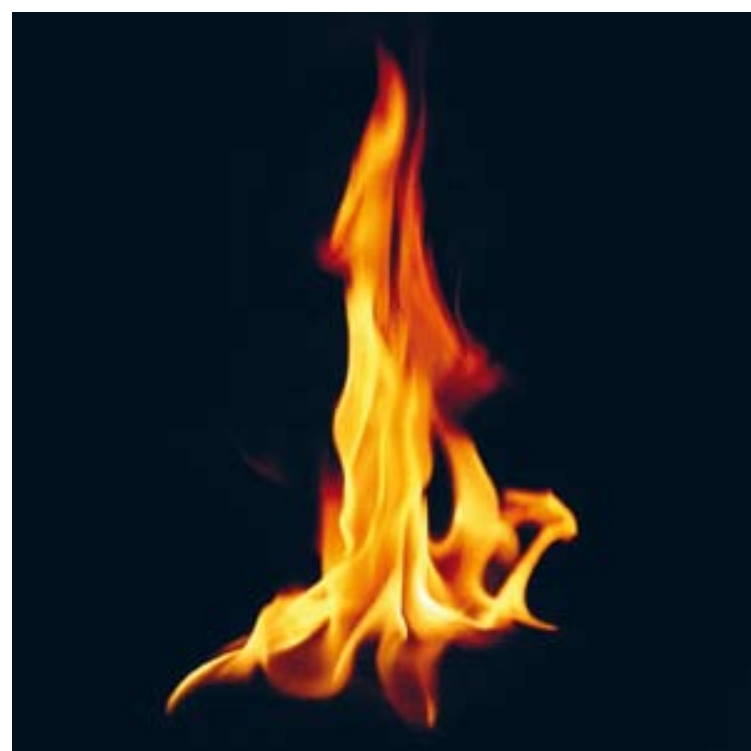

\section{Introduction}

Global energy demand in 2050 is projected to increase up to $150 \%$ over today's demand. Combustion processes for generating power, heat and process energy will be important in meeting the increasing demand for many years to come. These processes have significant $\mathrm{CO}_{2}$ mitigation potential using a range of technologies: improving power plant efficiency, using renewable fuels and carbon capture and storage.

Coal is an abundant and geographically widespread fuel, leading to a high security of supply and relatively stable energy prices. For these reasons, interest is significant in continuing to use coal as fuel for generating heat, power and process energy. Countries such as India and China will continue to expand electricity generation based on coal, and the coal reserves in the United States are estimated to last for about 250 years. For this reason, developing technologies to use coal in an environmen- tally sound way is important. Coal has been used for many years as a fuel, and the harmful emissions from coal combustion have been reduced dramatically in industrialized countries. The major unresolved issue involves $\mathrm{CO}_{2}$. Advanced coal technologies with carbon capture and storage will be critical to stabilizing $\mathrm{CO}_{2}$ emissions.

\section{Challenges and solutions \\ Improving efficiency}

Emissions of $\mathrm{CO}_{2}$ from power plants fired with fossil fuels (coal, oil, natural gas) can be reduced, renewable fuels can be used (biomass and waste) or the two can be combined by improving efficiency. This is mainly achieved by operating the steam cycle at higher temperature and pressure, which in turn requires using types of steel that can withstand these conditions.

Research, development and demonstration of new materials for increased steam temperature and pressure are thus key components of clean coal technology. New steel types promising up to $52 \%$ power efficiency are being developed as are materials that can withstand even higher temperatures. In addition to developing new materials for the steam cycle tubes, optimizing the coupling of the steam cycle itself is important.

Use of $\mathrm{CO}_{2}$-neutral fuels

Use of $\mathrm{CO}_{2}$-neutral fuels, biomass and waste, in highefficiency centralized electrical power plants is probably the most efficient way of using biomass to reduce $\mathrm{CO}_{2}$ emissions - especially if the power plant also supplies district heating. Denmark has been a first-mover in co-combusting biomass with coal. Since many types of biomass have high concentrations of alkali metals and chlorine and low energy density, using biomass at high-efficiency power plants introduces several challenges, such as: 
- how to transport large amounts of biomass;

- how to prepare the fuel;

- how to avoid accelerated superheater corrosion;

- how to avoid the deactivation of catalysts used for removing $\mathrm{NO}_{\mathrm{x}}$ from flue gas; and

- using fly ash for cement and concrete, as the alkali level must be within specified limits.

Based on intensified research and development since the mid-1990s, large power plants are now co-firing biomass corresponding to about $10 \%$ by energy at high temperature and pressure. Nevertheless, this fraction should be increased in the future. Conversion of coal-fired power plants to $100 \%$ wood combustion should be demonstrated, and the interactions between burning biomass particles and coal particles should be understood in detail to use a higher fraction of difficult-to-burn biomass and waste in generating electrical power. Finally, pyrolysis or gasification processes should be developed and demonstrated for pretreating more difficult fuels, such as straw, to increase the co-firing potential up to $100 \%$.

Within energy-intensive industry, such as cement manufacturing, the use of alternative fuels such as tires, waste and biomass is increasing rapidly, and novel technologies need to be developed to meet the requirements for specific fuels for the fuel used in the calciner and in the clinker-burning process.

$\mathrm{CO}_{2}$-capture processes

Drastically reducing the emission of $\mathrm{CO}_{2}$ from electrical power plants requires capturing the $\mathrm{CO}_{2}$ for subsequent storage. Several processes for capturing carbon are being considered.

Post-combustion capture of $\mathrm{CO}_{2}$. The power plant is basically unchanged, but a process is added before the stack to remove $\mathrm{CO}_{2}$ from the flue gas. Processes currently being investigated involve scrubbing the flue gas with alkanolamine solvents such as monoethanolamine or a cold aqueous solution of ammonia. An advantage of this process is that it can be used to retrofit existing power plants for carbon capture and storage. Nevertheless, this may use too much energy.

Pre-combustion capture. This process involves gasifying the fuel to a gas consisting mainly of $\mathrm{CO}, \mathrm{CO}_{2}, \mathrm{H}_{2}$ and $\mathrm{H}_{2} \mathrm{O}$, which is converted to $\mathrm{CO}_{2}$ and $\mathrm{H}_{2}$ in a catalytic reactor. Finally, $\mathrm{CO}_{2}$ is removed from the flue gas as in the post-combustion capture process. Existing pulverizedfuel plants cannot be retrofitted with this technology, which further requires developing a hydrogen gas turbine. The technology may enable co-production of electricity and liquid fuels (from syngas) and thereby facilitate the incorporation of more wind energy in energy systems.
Oxyfuel combustion. This technology involves combusting the fuel in pure oxygen, obtained from an air separation plant. The combustion process leads to a flue gas consisting mostly of $\mathrm{CO}_{2}$ and water. Water is easily removed by condensation, but how the remaining levels of trace species of $\mathrm{NO}_{\mathrm{x}}$ and $\mathrm{SO}_{\mathrm{x}}$ influence the quality of the $\mathrm{CO}_{2}$ for storage is unclear. Compared with the post-combustion capture process, implementing the oxyfuel combustion technology in existing power plants fired by pulverized coal requires changing the plant. Nevertheless, the technology may be developed further to lower energy consumption considerably.

All these technologies reduce the current efficiency of a conventional power plant by about 8-10 percentage points. This clearly makes achieving the highest initial efficiency even more important to reduce the relative loss and to develop the method to reduce energy consumption.

Newer methods using carbonate-looping processes at higher temperatures may turn out to be an even more attractive solution in the future.

\section{Implementation issues}

At the global, regional and national levels, action is being taken to reduce greenhouse-gas emissions. Policies that impose a real or implicit price on carbon could create incentives for producers and consumers to significantly invest in products, technologies and processes with low greenhouse-gas emissions. Such policies could include economic instruments, government funding and regulation.

All stabilization scenarios indicate that the energy and industry sectors would supply $60-80 \%$ of the reduction in greenhouse-gas emissions, and it is assumed that technological and structural changes are going to occur during this century. Investing in and worldwide deployment of technologies with low greenhouse-gas emissions through public and private research, development and demonstration will be required for achieving stabilization targets and reducing costs. A wide range of technologies with low greenhouse-gas emissions - both ones currently available today and those expected to be available in the coming decades - need to be implemented to reach the stabilization target. The contribution of various technologies to reducing emissions will vary over time and by region. 


\section{Improving efficiency}

New materials for high-temperature and -pressure stream cycles need to continue to be developed - also for systems fired with biomass and waste with high flue gas concentrations of alkali metals and chlorides. Process layout should be improved further to even out the heat flux to the high-temperature steam tubes.

For industrial processes, issues mainly relate to reducing heat loss and improving the use of waste heat. In particular, the use of waste heat in the product gases needs to be improved, by improving process layout, improving heat-exchanger equipment, reducing gas flow and/or using the waste heat to co-produce other products - electricity or liquid fuels.

\section{Using $\mathrm{CO}_{2}$-neutral fuels}

Research on pure biomass firing for wood fuels at high temperature and pressure and co-combusting coal and biomass or waste should be carried out, focusing on all operational issues, such as combustion characteristics, pretreatment, corrosion, using fly ash and the deactivation of selective catalytic reduction catalysts. Simple atmospheric pressure gasification or pyrolysis processes for difficult biomass types or waste should be further investigated, developed and demonstrated.

For energy-intensive industries, such as cement plants, potential fuel candidates are municipal solid waste, solid and liquid waste from industrial production and waste material from forestry and agriculture. The main challenges in designing cement production processes for using waste as fuel are the low and varying specific heating value of waste and the inorganic species contained in the waste: chlorine and alkali metals.

\section{Carbon capture}

No commercial technology is available at the capacity required for capturing $\mathrm{CO}_{2}$ from a large-scale modern power plant. Further, all the competing technologies reduce efficiency significantly and similarly. The ultimate best process cannot yet be determined. However, the post-combustion capture processes are directly applicable at existing power plants, which indicates that the first plants may be retrofitted with these processes. The other technologies may be the best processes for future installations and therefore deserve funding for research and development.
Further enhancing the development of carbon capture and storage technologies requires performing research and tests on new absorber chemicals for post-combustion conditions, developing new and more efficient processes for separating air to isolate oxygen, developing new process layouts for oxyfuel combustion and optimizing emission control (removing $\mathrm{NOx}$, desulfurizing flue gas and removing dust). For cement production and for some electrical power plants, the focus is on using the carbonation-calcination cycle for capturing $\mathrm{CO}_{2}$, since limestone is already an important raw material in cement production. Several process and design issues need to be addressed before the technology can be commercialized, including the design of fluid bed reactors, optimizing parameters and exploring the potential of co-producing cement and electricity. 


\section{Mitigation}

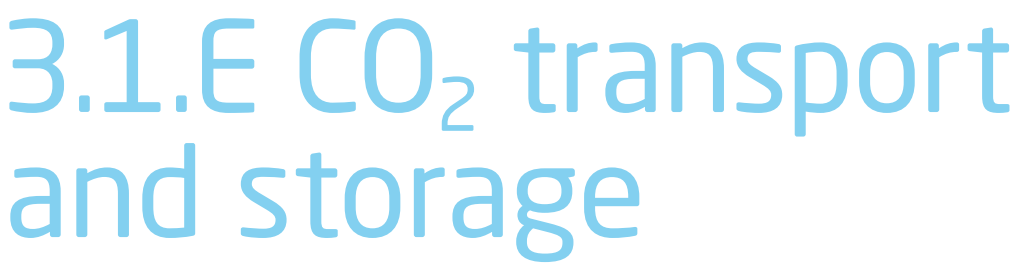

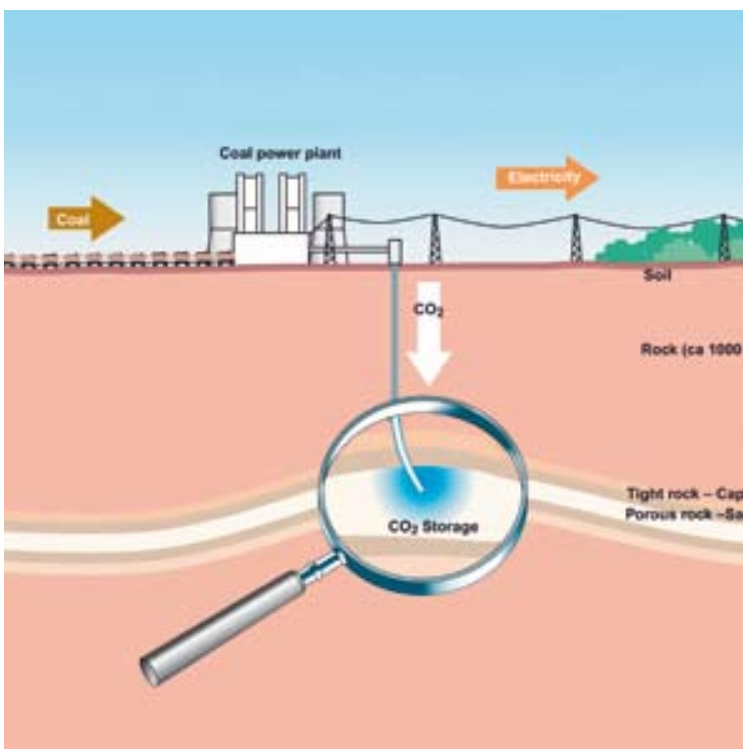

Source: Vattenfall

\section{Introduction}

Storage of $\mathrm{CO}_{2}$ is a rapidly developing technology, especially storage combined with enhanced oil and gas recovery. Several successful storage projects combined with enhanced oil and gas recovery have been reported in the United States and Europe. Further, geological storage in saline aquifers has been carried out for more than 10 years, and several new storage projects are under consideration.

\section{Challenges and solutions}

The storage sites are distributed non-uniformly around the world. Finding new potential storage sites (such as depleted natural gas fields, saline aquifers and oil reservoirs) is therefore an important challenge. Another option is developing novel technologies for storage, such as combining the $\mathrm{CO}_{2}$ storage with producing geothermal heat or extracting water.
Another challenge related to the non-uniform distribution of the potential storage sites is establishing systems for transporting $\mathrm{CO}_{2}$. The future is in decentralizing energy production: in particular, combusting biomass or biomass together with coal is one option. Decentralizing energy production creates new challenges for collecting $\mathrm{CO}_{2}$ and delivering it to the storage sites.

A main challenge related to storage is corrosion. Corrosion can occur in several places in the processes related to $\mathrm{CO}_{2}$ capture and storage. In particular, injection and production wells on the reservoirs used for storage should be protected against carbonic acid. Maintaining well integrity is a real and costly problem. Special carbonic acid-resistant materials should be used there. The corrosive effects of $\mathrm{CO}_{2}$, including possible effects from impurities, should be studied and considered. The challenges should be met by applying or developing new materials. Storage in depleted oil reservoirs may require sealing closed wells with resistant cement.

Storing $\mathrm{CO}_{2}$ in underground reservoirs and especially onshore storage requires technologies for monitoring and managing uncertainty. A general fear of $\mathrm{CO}_{2}$ being stored under people's homes has to be dealt with. Advanced static geological modeling, involving uncertainty management, and as dynamic modeling of spreading the $\mathrm{CO}_{2}$ underground are required to ensure safe storage over long time intervals. Further solutions to this challenge might include permanent monitoring in injection wells and on the surface. Pilot programs have conducted surveillance of the vegetation by airplane or satellite.

Special challenges arise in the interaction between geochemistry and geophysics. $\mathrm{CO}_{2}$ may react with rock and produce reservoir subsidence, rock compaction and the formation of wormholes and fractures. $\mathrm{CO}_{2}$ may dissolve in water and diffuse through an aquifer. Under enhanced oil and gas recovery, the supercritical $\mathrm{CO}_{2}$ may mix with oil, causing swelling, precipitation of 
asphaltenes and other effects. $\mathrm{CO}_{2}$ has been injected for enhanced oil recovery and has proven to be efficient. The rule of thumb states that it should be tried whenever water flooding is efficient. A future challenge is injecting $\mathrm{CO}_{2}$ for enhanced oil recovery from the zones where it is at low saturation and even under residual saturation. Applying advanced enhanced oil recovery methods requires better understanding of the pore-scale behavior of $\mathrm{CO}_{2}$ and improved understanding of long-term prediction of geochemical and fluid dynamics effects.

Developing new storage projects requires scaling the laboratory experimental results from laboratory samples to pilot projects and, finally, to industrial scales.

\section{Implementation issues}

Progress in storage projects in Denmark and in the rest of Europe requires having the legal framework in place. This requires political decisions. Issues related to locations, $\mathrm{CO}_{2}$ credits, monitoring and long-term liability must be addressed. Government permits will clearly require proper environmental and safety assessment. Public acceptance will also depend on this, which will require further work in monitoring and verification.

Mathematical modeling of long-term storage, which includes reservoir dynamics - flow with chemical reactions, phase equilibriums and non-equilibrium processes such as diffusion - need to be developed.

Monitoring of potential leaks in wells and at the surface is a separate challenge for which technology needs to be developed.

The oil and gas industry has already solved many of the technological problems, and massive technology transfer is needed. Nevertheless, the solutions must be valid for the problem. Transferring and adapting existing solutions to the long-term storage of $\mathrm{CO}_{2}$ will require significant effort. 


\section{Mitigation}

\subsection{F Sustainable buildings}

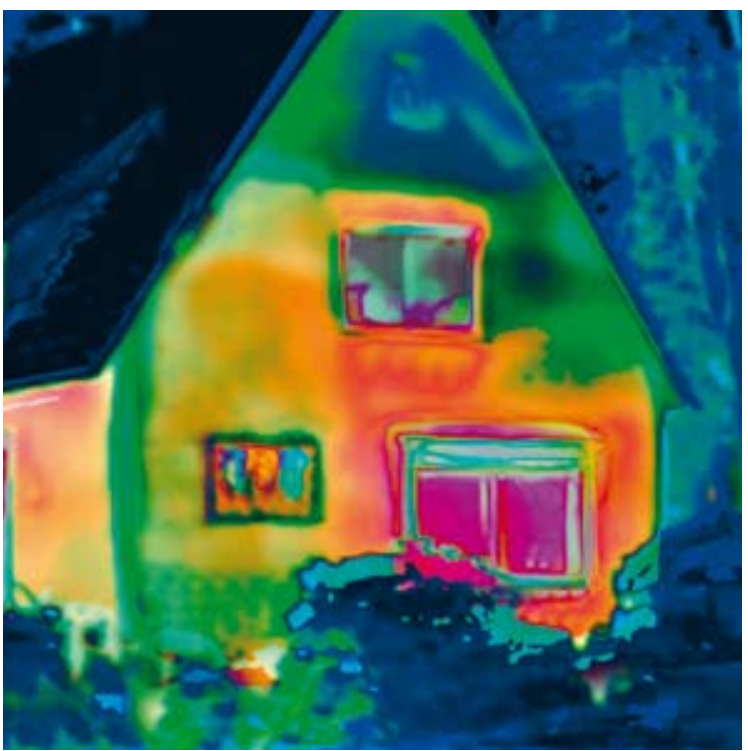

\section{Introduction}

The energy used in buildings for heating, cooling and lighting is decisive for the global energy system. Whereas the building stock in industrialized countries is dominated by and will continue to be dominated by the buildings already built, the global perspective is different; most of the buildings in developing countries in 2050 do not yet exist. The DTU Workshop on Sustainable Buildings held on June 19, 2008 addressed these challenges.

In developing countries, urbanization and economic growth will increase energy use in buildings. Achieving the United Nations Millennium Development Goals and improving the living conditions for the growing global population will result in several billion people moving into cities in the coming decades. Thus, energy-efficient new buildings are the main goal in developing countries.

In industrialized countries, energy use in buildings is primarily associated with the existing building stock. In the European Union, buildings account for about $40 \%$ of the energy use allocated to end-users. About $1 \%$ of the building stock in industrialized countries is renewed annually, strongly fluctuating with economic cycles. Thus, nearly all existing buildings will also exist in 2050 .

Energy use in buildings in the European Union is distributed as follows:

- two thirds for heating and cooling; and

- one third for lighting and appliances.

Energy use in buildings is dominated by heating demand, but improved insulation, increased energy efficiency and climate change will gradually reduce this to the same level as the energy demand for ventilation, cooling and lighting. As most of the new buildings globally will be located in warm climates, cooling and lighting will become dominant globally. Constantly focusing on improving operating practices is thus required for improving energy efficiency in buildings.

Most buildings are located in cities, and an increasing proportion can be linked to collective energy supply systems (district heating and cooling). The buildings are on the demand side of energy systems and should be considered an integral part. In the future, the buildings may also be able to supply and store energy (local heat and electricity storage and supply). Thus, supply must be planned to be integrated with demand. Buildings should be seen as an integrated part of intelligent energy systems (section 3.1.1). Given that most buildings built today will also be in operation long after 2050, planning should be based on future supply systems free of greenhouse-gas emissions.

Spatial planning influences energy use in buildings. Spatial and energy planning are crucially important for the overall energy performance of buildings. Energy plans that favor network-based energy solutions in built-up areas are more efficient than stand-alone solutions; even the shadows from neighboring buildings influence direct energy use. Further, overall spatial planning critically influences the pattern of transport: a 
compact city with integrated energy-efficient solutions generally uses less energy and emits fewer greenhouse gases than a scattered city with increased transport.

\section{Challenges and solutions}

Achieving climate goals requires that the future energy supply for buildings be carbon neutral. This can only be achieved if renewable energy is combined with massive energy conservation in the existing building stock and only if all new buildings are energy efficient. The DTU Workshop on Sustainable Buildings showed that improving energy storage options and intelligent management of energy use in buildings benefit renewable energy systems. The key contribution from the building sector thus is negajoules - massive energy savings and storage and back-up opportunities.

\section{Great potential to conserve energy}

International research has consistently shown that the existing building stock has great potential for conserving energy. Alone in Denmark, DTU research has shown that energy use in buildings can be reduced by up to $80 \%$ by 2050 and that this is largely economically attractive, especially when combined with general maintenance. Thus, the challenge is to combine technical innovation with economic optimization and to ensure that the solutions are implemented in general and before 2050 . Governments must introduce incentives and regulation that ensures that the conservation potential is exploited. New incentive schemes must be developed, and investment in energy conservation in the building sector needs to be balanced with investment in energy conservation in other sectors.

\section{The basic technology is here}

Houses can be built today that use $90 \%$ less energy than existing buildings at a small marginal cost and without compromising architectural quality, usability or indoor climate. There is great potential for further technical innovation within the building sector that may be combined with economic optimization. National regulation and incentives are also needed here to ensure a rapid decline in the energy used for the building stock.

More research and development needed

Innovation and implementation of new technology are not simple due to the tradition-based (in contrast to knowledge-based) building sector. The following potential technical innovations for developing costeffective solutions have been identified:
- highly insulating building envelopes for new buildings and for retrofitting;

- dynamic window systems, including solar shading with a positive net energy gain in the heating season, minimum solar gain in the cooling season and high transmittance of diffuse daylight;

- ventilation systems that provide a healthy and comfortable indoor environment with heat recovery and such a low pressure drop and energy use of the fan that the ventilation system can also be used for venting and night ventilation to cool the building;

- lighting systems based on new energy-efficient lightemitting diode (LED) light sources that are designed and controlled to be used only when needed for human activities when daylight is insufficient;

- systems for heating rooms and domestic hot water that only need a supply temperature of $50^{\circ} \mathrm{C}$ and have low and uniform energy consumption during the day;

- low-temperature $\left(50^{\circ} \mathrm{C} / 20^{\circ} \mathrm{C}\right)$ district heating systems that can supply low-energy houses with heat from multiple renewable heat sources with a heat loss of less than $15 \%$ and at a competitive cost;

- solar heating systems combined with heat pump systems to supply heat to buildings outside areas with district heating;

- systems for intelligent control and continual commissioning of the technical building services and heating supply systems based on dynamic calculations of the indoor environment and energy use of the buildings for predicted and measured weather data; and

- systems for integrating intelligent buildings into intelligent energy systems.

\section{Implementation issues}

Most implementation issues are economic and societal. However, continued research, development and demonstration of energy conservation technology are needed to accelerate implementation and reduce its costs.

\section{Government regulation is needed}

The following actions to implement technical innovation in the building stock have been identified:

- strengthening building regulations on energy use and the indoor environment for both new and existing buildings;

- adopting local energy plans for cities related to heating supply by district heating;

- carrying out demonstration projects to validate technology and facilitate implementation in the building sector; and

- enhancing education and making the building sector knowledge-based. 
The challenge is to bring the individual technologies into use through an integrated design process that reconciles energy conservation, indoor climate, construction requirements, architecture and end-user demands with good overall economy based on long service life and low cost.

The time scale is large

Most existing buildings will also be in use in 2050 . Long-term planning is needed for both the individual building owners and the energy system planners. However, the planning basis is not rational today, especially for retrofitting.

The challenge is to develop system models that allow individual building owners to make rational decisions on energy renovation and energy system designers on energy demand systems. Such system models should include life-cycle cost analysis based on various energy supply and cost scenarios. As the decisions reach into the long term (30-60 years), traditional economic calculations do not suffice; government guidelines should be developed that limit the use of energy from fossil fuels in both new and existing buildings and require the use of energy supply systems to ease the decision-making process for building owners.

\section{Buildings are part of energy systems}

The vast majority of buildings are linked to collective energy systems (electricity, natural gas and district heating and cooling). This calls for integrated energy planning. Collective energy solutions are more efficient than single-house solutions. In future intelligent energy systems, buildings will become not only end-users but also store and produce energy.

Challenges include the interaction between the perspectives of the individual building owners and the energy suppliers. New incentives and regulation are needed to develop overall efficient systems that balance investment between sectors. This is especially important in the building sector, where the renewal time is much greater than normal economic time scales. Technical research and development challenges include:

- replacing existing building stock with low-energy buildings or retrofitting;

- implementing low-demand energy supply systems (district heating and cooling);

- designing intelligent energy systems that can accommodate and use energy storage and production in buildings; and

- developing innovative organizations such as energy service companies and public-private partnerships.
Buildings and spatial planning

Sustainable buildings and sustainable cities need to be integrated, as spatial planning sets the conditions for individual buildings, and conditions for solar and wind energy and ambient noise need to be considered when sustainable buildings are designed.

The major challenges are:

- policy and interest conflicts, such as how to balance centralized compact cities with the desire to maintain good conditions for solar and wind energy and low ambient noise in urban areas; and

- developing rational models that integrate energy, transport and spatial planning to compare scenarios for decision-making. 


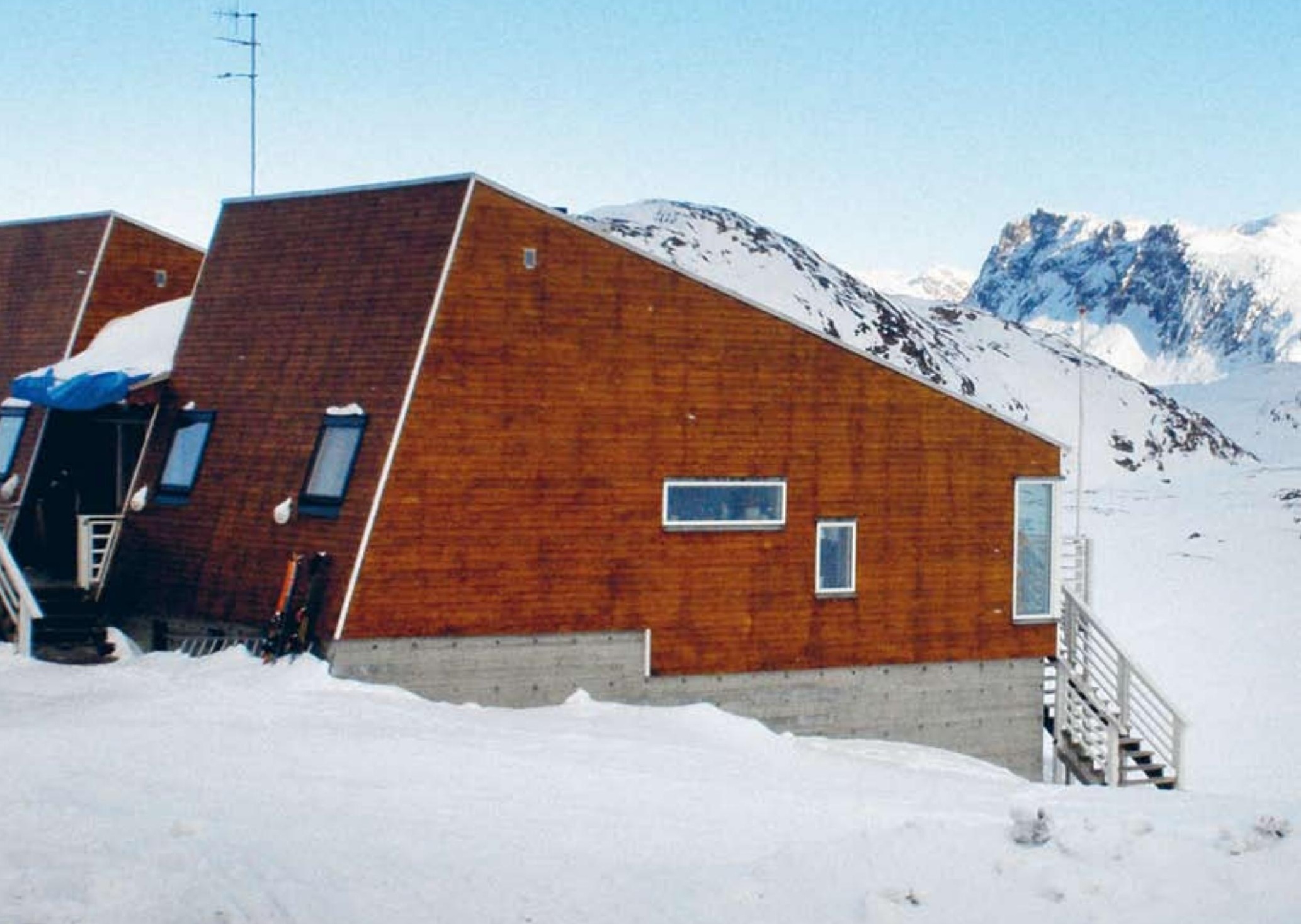




\section{Mitigation}

\subsection{G Transport}

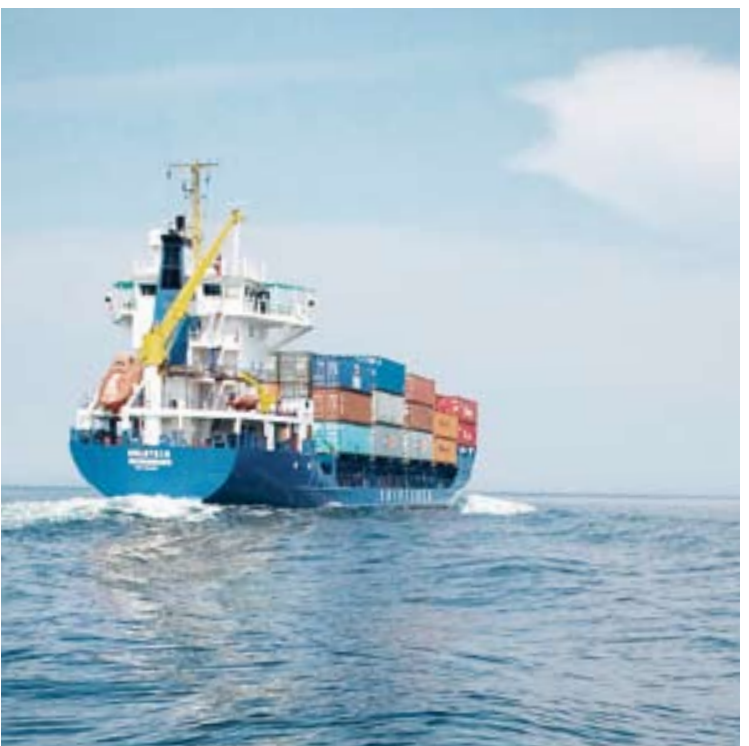

Introduction

Transport plays a crucial and growing role in world energy use and emissions of greenhouse gases. Motorized vehicle transport relies almost $100 \%$ on fuel made from petroleum. In 2004, the energy used for transport comprised $26 \%$ of total world energy use, and transport was responsible for about $23 \%$ of global energy-related greenhouse-gas emissions.

Economic development and transport are closely linked. Development increases transport demand, and the availability of transport stimulates even more development by enabling trade and economic specialization. Industrialization and growing specialization have created the need for transporting large quantities of goods and materials over substantial distances; accelerating globalization has greatly increased these flows. Worldwide transport activity will continue to grow rapidly for the foreseeable future, especially in rapidly growing economies. Integrating the transport sector into energy systems and increasing the share of fuel based on sustainable energy are therefore necessary.

\section{Challenges and solutions}

The challenge for researchers and professionals in transport will be to develop planning tools and technological solutions that can provide the international community with the options to achieve much lower $\mathrm{CO}_{2}$ emissions while maintaining very high mobility for goods and people. The international research community has the necessary competencies in many key fields, but the research needs to be strengthened and internationally coordinated to obtain optimal effects.

\section{Implementation issues \\ Intercontinental marine transport}

The $\mathrm{CO}_{2}$ emissions from marine transport account for $3-4 \%$ of global $\mathrm{CO}_{2}$ emissions. There are three important pathways for reducing $\mathrm{CO}_{2}$ emissions from intercontinental marine transport.

- Introducing operational measures, including slow steaming, awareness of energy-efficient operation (decision support systems for the crew) and route planning, including logistical planning. $\mathrm{CO}_{2}$ reduction potential: $10-15 \%$.

- Technical measures, including better propellers, hull forms with less resistance, new types of hull paint, introducing wind powering, using solar energy (not yet very well demonstrated) and improving diesel engine technology. $\mathrm{CO}_{2}$ reduction potential: $10-15 \%$.

- Market-based measures: the two discussed in the International Maritime Organization to reduce $\mathrm{CO}_{2}$ are a global emission-trading scheme and an international fund for greenhouse gas emissions from ships. $\mathrm{CO}_{2}$ reduction potential: $10-15 \%$. 


\section{International passenger air transport}

Increased efficiency of airplanes. Airplanes have become $70 \%$ more efficient during the last 40 years, but the theoretical limit has not been approached. Current engines are about $60 \%$ efficient compared with theoretically perfect combustion. Materials could be improved and be lighter and stronger. Aerodynamic improvements can make wings more efficient and reduce the drag. Hydraulic systems in the airplanes could be replaced by electric systems. Energy-harvesting technologies such as piezoelectric, thermoelectric and solar can be applied much more. Fuel cells could produce the electricity needed on board.

Lower flight speed. Reducing speed is an efficient way to reduce $\mathrm{CO}_{2}$ emissions from aviation. This implies optimizing designs and air traffic management. Renewable energy in airplanes. Alternative fuels include bioethanol, methane and liquid hydrogen. In the long term, many options are being researched, such as fuel cells, hydrogen and even different kinds of solar energy. Optimizing overall air traffic management and flight control systems. Air traffic management is the first step in reducing $\mathrm{CO}_{2}$ emissions, followed by next-generation aircraft, the goals of ACARE (Advisory Council for Aeronautics Research in Europe) for 2020 (reducing $\mathrm{CO}_{2}$ emissions by $50 \%$, NOx emissions by $80 \%$, external noise by $50 \%$ and an environmentally sound aircraft life cycle) and, finally, alternative fuels. The IPCC studies showed that reductions of $2-18 \%$ are possible, of which $6-12 \%$ are related to air traffic management.

Policy instruments in aviation. A global consensus and global goals are needed to reduce the $\mathrm{CO}_{2}$ emissions from passenger air transport.

High-speed trains on short-haul routes: Short-haul transport (travel time 3 hours for less than $800 \mathrm{~km}$ ) can be carried out more efficiently by using other means of transport such as high-speed trains. The complementary effects of different means of transport need to be exploited. The cooperation between rail and air transport could become more efficient through common check-in systems and other measures.

\section{Private car transport}

The demand for private car transport will not decrease in the future but rather rise steeply, given increasing income, especially growing rapidly in Asia and - potentially - in Africa. Hence, the only solution appears to be new technologies for vehicle transport that can efficiently use non-fossil fuels.

In the short-term, improving efficiency has an important role by decreasing fuel consumption and thereby $\mathrm{CO}_{2}$ emissions.
Flexibility in future sustainable energy systems is a driver for alternative fuels for transport. One solution is electrical vehicles using batteries charged from sustainable sources. Further, electrical vehicles are highly energy efficient. The limited availability of renewable sources places a strong focus on energy efficiency, and rapid introduction of battery-powered cars can contribute to this. In the long-term, fuel cells and hydrogen might become an option in parallel with electric vehicles. Road user charges are very likely to be imposed in many European countries in the coming years. This can not only reduce $\mathrm{CO}_{2}$ emissions but has potential as a traffic management scheme for reducing congestion and the local detrimental effects of transport.

\section{Road-based freight transport}

Freight transport mostly operates in urban areas (within cities) and interurban (between cities and regions). The diesel engine is still the most efficient propulsion system for road freight. Natural gas is an alternative fuel with some potential in urban and, to some extent, interurban freight transport. Electric trucks are not an option for large trucks given current battery technology but may have potential in urban distribution with small vans. Several things can improve fuel efficiency in road freight. Training drivers in energy-efficient driving techniques, allowing larger vehicles and reducing average driving speed are three initiatives. Another potential in the short term is further use of taxes and charges. This instrument will increase focus on delivering better and more intelligent transport solutions with lower energy consumption. 


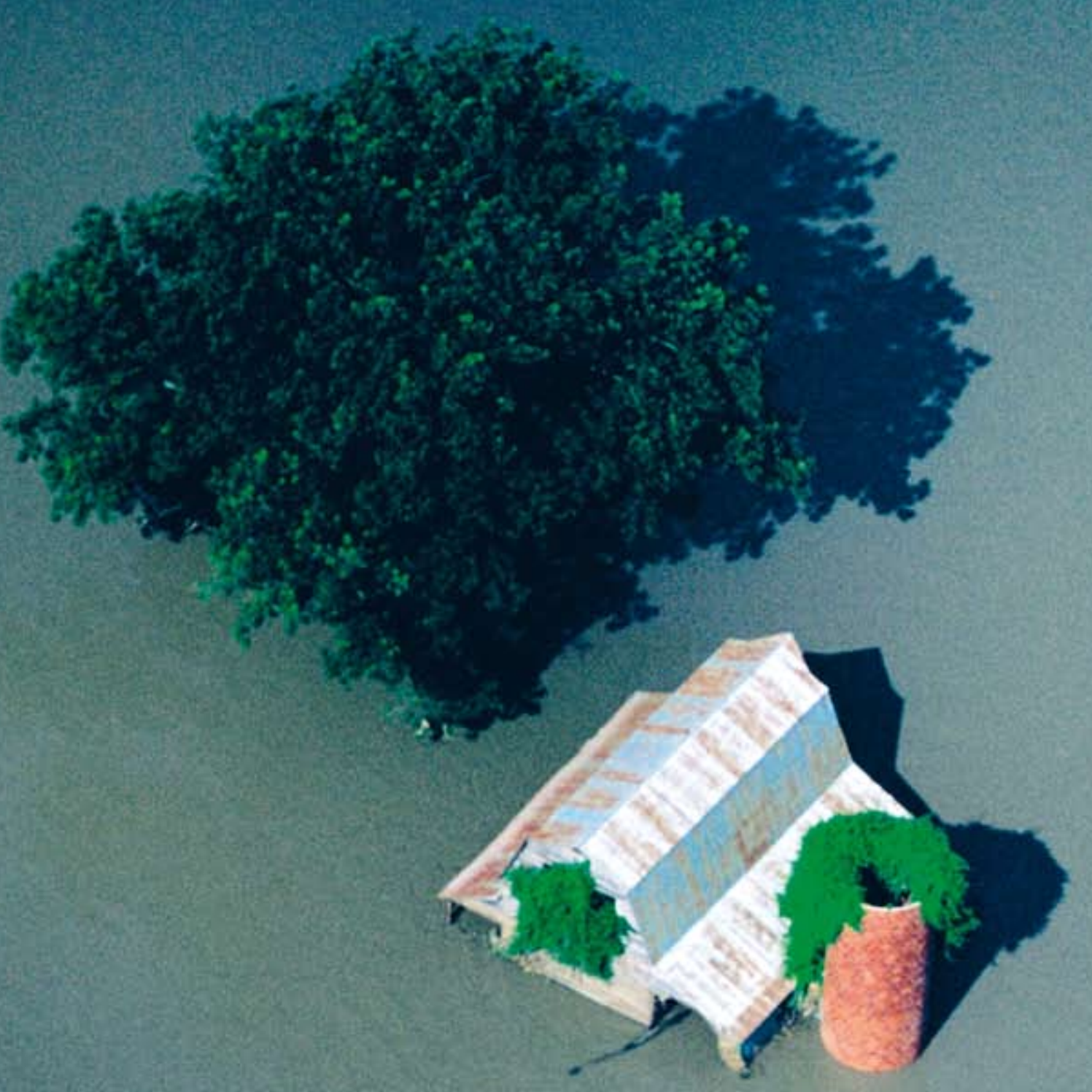




\section{Impact assessment and adaptation}

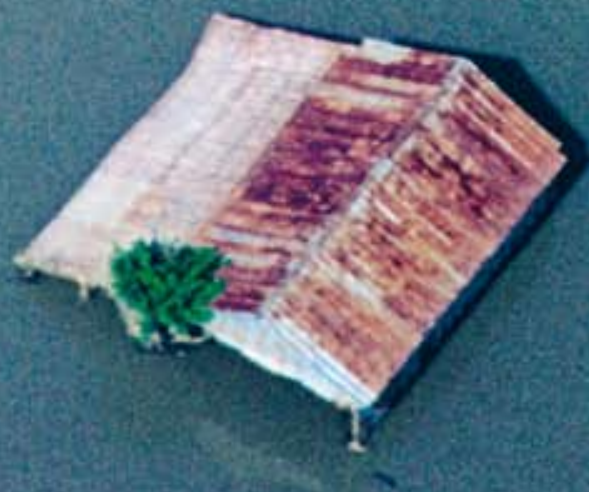




\section{Impact assessment and adaptation}

Mitigation measures and adaptation measures must be viewed complementarily to meet the climate change challenge. Even if policy-makers reach international agreement on restrictive emission policies, the climate will change considerably during the next several decades.

Global climate change will cause a rise in sea level, coastal erosion, changes in biosystems and ocean circulation and various other effects. Different regions, ecosystems and societies will face different problems, and extensive impact assessment and modeling are therefore crucial in understanding the potential effects of climate change.

The regional effects of climate change are poorly known today, which means that management and action must be carried out based on considerable uncertainty, and many climate change policies must be considered as managing risk.

Vulnerability to climate change is determined by the potential effects of climate change and the adaptive capacity of society, which depends on socioeconomic and institutional capacity and willingness to adapt. Adaptation measures accordingly can be geared to reduce general vulnerability by reducing the potential effects of climate change and by increasing society's adaptive capacity.
The Synthesis report of the IPCC Fourth Assessment Report concludes: "There is high confidence that neither adaptation nor mitigation alone can avoid all climate change impacts; however, they can complement each other and together significantly reduce the risks of climate change." Based on this perspective, the following sections provide examples of how to improve climate change impact assessment and climate change adaptation in specific sectors. 


\subsection{Recommendations on impact assessment and adaptation}

The DTU workshops have investigated and discussed four topics related to impact assessment and adaptation:

- monitoring and climate predictions;

- ecosystem productivity;

- infrastructure; and

- animal health and food safety.

Adapting to a changing climate is a prerequisite for almost all sectors in a modern society. Although the need for and means of adaptation vary from sector to sector, two strategies appear generally viable:

- a proactive approach in which the uncertainty of the future is managed rationally by planning future systems and infrastructure in a versatile manner using, for example, risk management tools; and

- a reactive approach in which each sector sets up contingency measures, thus increasing the capacity of the sector to react to effects of or threats from the changing climate or to resist the adverse effects of the changing climate.

Adaptation in some areas may be primarily managed by developing new technology, whereas in other areas the adaptive capacity largely depends on socioeconomic mechanisms and the ability and willingness of society and people to adjust.

In any case, predictive capacity is vital to assess the effects of a changing climate. The predictive capacity of today's climate models still needs to be improved, both on the global scale and on the regional scale. The IPCC provides a framework for developing global-scale models, but developing better regional models still requires considerable effort.

On both the global and regional scales, calibrating and validating the climate models - for example through satellite observations - is important. Reliable prediction models require consolidated and continuous data from the regional and global monitoring of climate change. Carefully monitoring the cryosphere can provide key input to such models, since the cryosphere plays a significant role in the Earth's climate system. Hence, reliable data on the changes in sea ice and the ice sheets will improve the predictive capacity of not only regional but also global climate models. Further, the degradation of permafrost in the Arctic leads to a huge emission of greenhouse gases, which may become an important parameter in developing climate models.

Another important parameter in developing climate models is the global carbon and nitrogen cycles, which are strongly affected by the changing climate. Climate change inevitably implies change in the natural environment, such as natural resources and ecosystems. Increasing temperatures will gradually change biodiversity and conditions of living and production and thus becomes a condition of living to which people must adapt. The time scale for such changes may be decades rather than centuries, and proactive measures therefore need to be identified if maintaining or even increasing productivity from agriculture and aquaculture is desired to avoid further jeopardizing the climate. However, climate change is altering many of the physical, chemical and biological processes that govern the net flux, and the balance may therefore change. Since this would greatly affect future greenhouse-gas concentrations, it must be a high priority area for research.

Alongside the improved climate models, impact models needs to be developed and customized to the specific area of interest, to enable reaction and taking the necessary adaptive measures. The effects of climate change can be assessed based on prediction models for environmental parameters such as temperature, rain, sea level and wind. For some sectors, such as infrastructure, the climate parameters more or less directly correspond with the effects, since the environment - water, wind and temperature - directly causes most of the effects on infrastructure. Hence, in such cases, impact assessment is generally straightforward (yet challenging), and the adaptive measures may be readily specified given high-quality models and data. For other areas, such as food safety and animal health, climate change has more 
indirect effects, being a product of interaction between the climate and a system that is inherently complex and dynamic. In such cases, impact models need to be developed to address even greater uncertainty than that embedded in the climate models.

In both cases, uncertainty can be managed by means of assessing and managing risk. The input to risk models is events (climate-related or other) and their likelihood and uncertainty. While climate models forecast the future environmental parameters, the traditional design and planning models are using hindcast data to estimate the extreme events and the variation within such events. These hindcast models are developed for stable climate and thus assume that the future resembles the past. However, the current rate of climate change necessitates prediction models that can manage the uncertainty of the future. The climate models are based on statistical prediction models and in theory can supply the necessary input for estimating the return periods of an extreme event such as a storm of a magnitude that would only occur every 10,000 years. Nevertheless, the statistical distribution of, for example, wave heights within a storm event needs to be assessed as well. The currently available models still do not fully account for this uncertainty. Further, the overall uncertainty of the models will increase, and the cost of being more conservative in design and planning needs to be considered or a greater risk of failure or exceeding limit values needs to be accepted. For most areas, this way of addressing uncertainty in design and planning will therefore require a shift in paradigm in close dialog with those developing the climate models.

The time scale of climate change is assessed to be decades and centuries. During that period the frequency of extreme events will increase. The need for adaptation must therefore be considered on different time scales and involve decisions about the acceptable level of risk in the future.

The built environment, including infrastructure and buildings, has a long lifetime of up to 100 years or more, and many of these assets are vulnerable to climate change. Including assessment of climate change risks in the design of infrastructure investment is therefore recommended. Such assessment can consider return periods for extreme events and the cost of adapting the projects to a changing climate.

For the existing infrastructure, climate change adaptation will imply retrofitting to meet the new climate: strengthening structures, increasing the capacity of sewers and other measures.
For future infrastructure, adaptation may simply comprise timely adjustment of design guidelines to climate change. Further, considering the time scale of several decades, migration from regions, such as coastal zones exposed to increased climate threats, may reduce the need for extreme adaptive design measures but instead significantly change the basis for spatial planning. The challenging aspect of the time scale is realized when the lifetime of urban systems is considered; even if the individual infrastructure element (such as a house, a railway or a bridge) has a lifetime of 100 or more years, a city as a system has a lifespan of centuries. For example, the new Ørestad City in Copenhagen is being built in a low-lying area already protected by dikes. Based on the predicted sea-level for the centuries to come, this planning decision has forced future generations into an ever-increasing investment in protection from this water. Establishing models and means for promoting robust urban development to adapt to climate change is an interdisciplinary challenge that should be faced by spatial planners, architects, engineers, economists, sociologists and other professionals. 


\section{Bry. II}

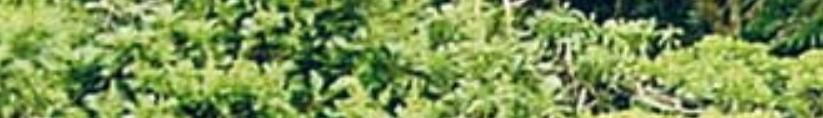

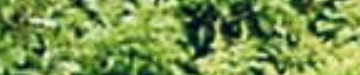

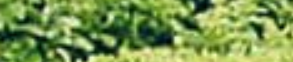

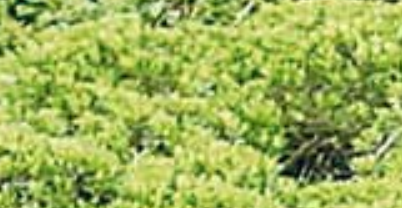

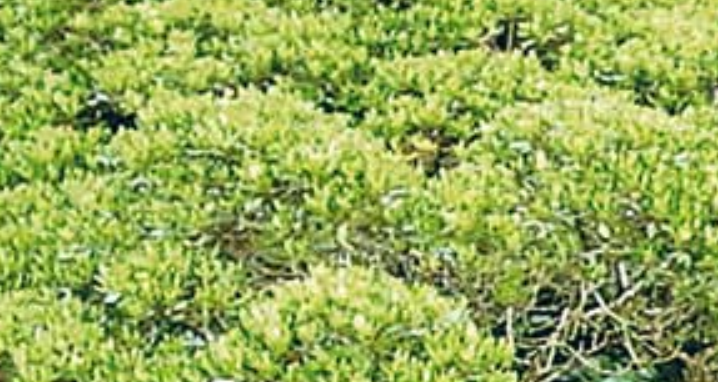

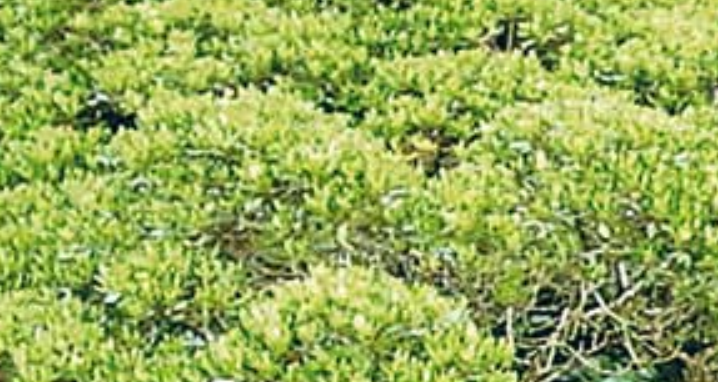

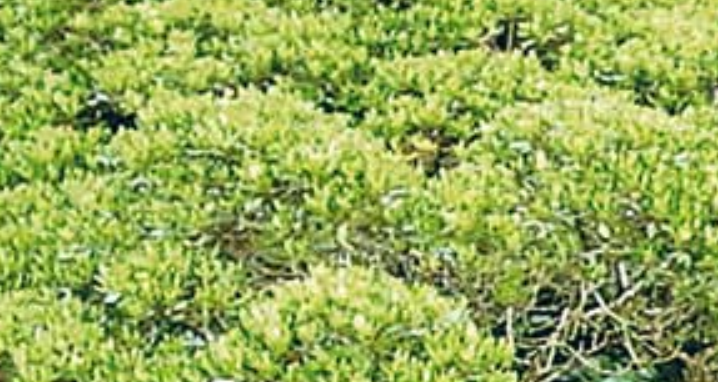

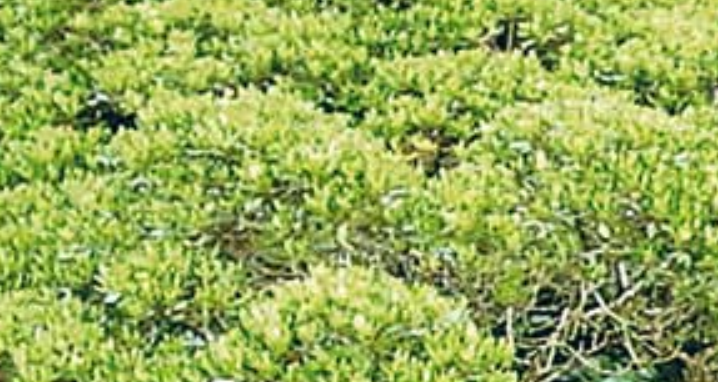

(7)

$2 x-4-2+5$

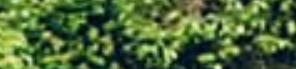

\section{2.t.}

ind

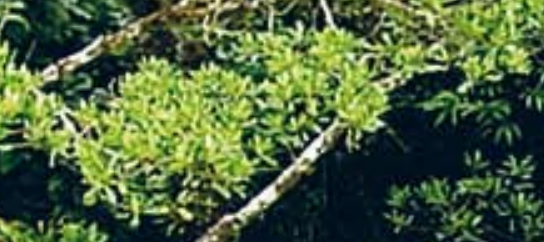

$x^{2} x^{2}$

7 .

$\sin$

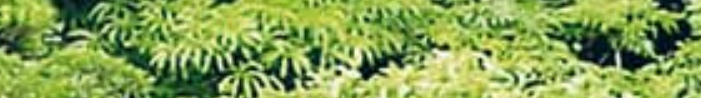

is 350

20 m

itsin:

15.

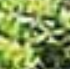

4.45

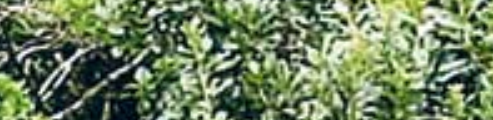

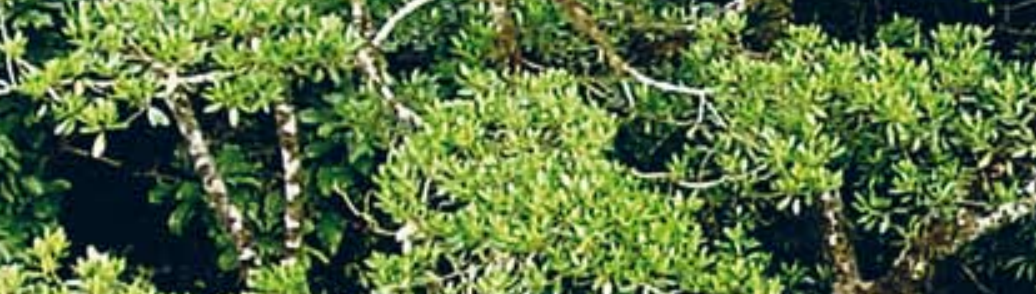

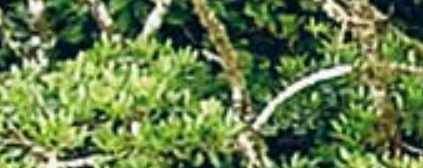

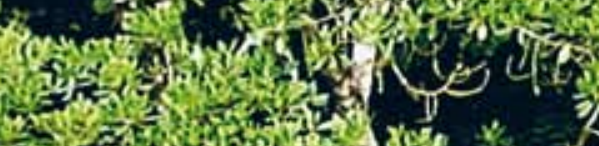

con

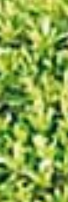

ats.

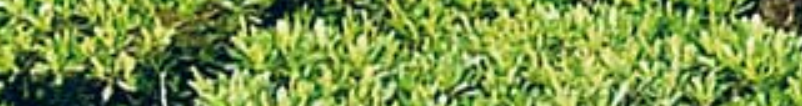

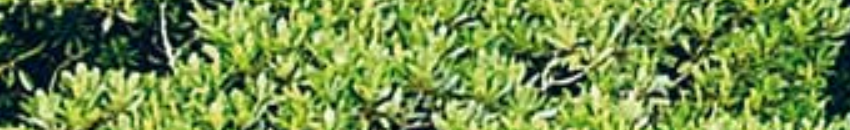

10. 15.5.5. (5) T. 50 .

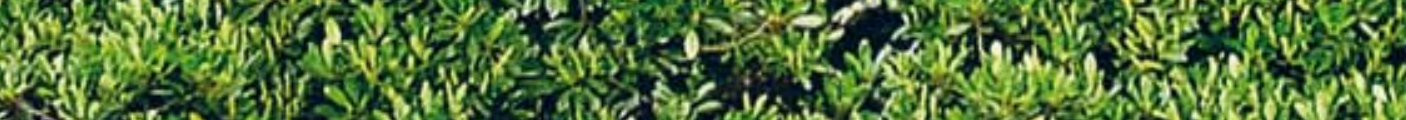

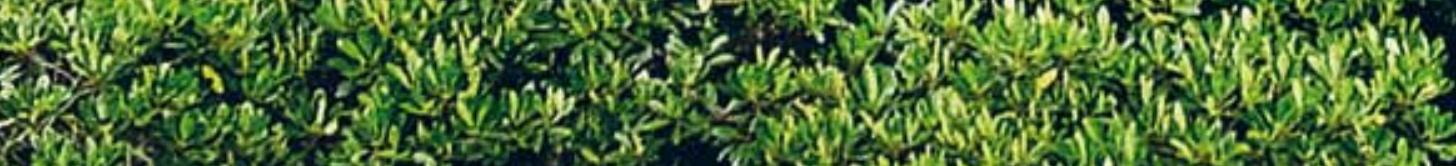

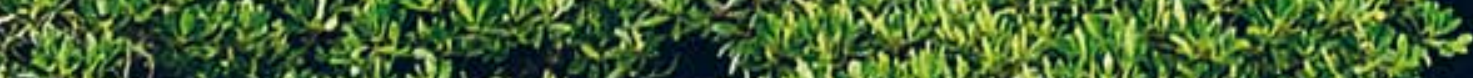




\subsection{A Monitoring and climate predictions}

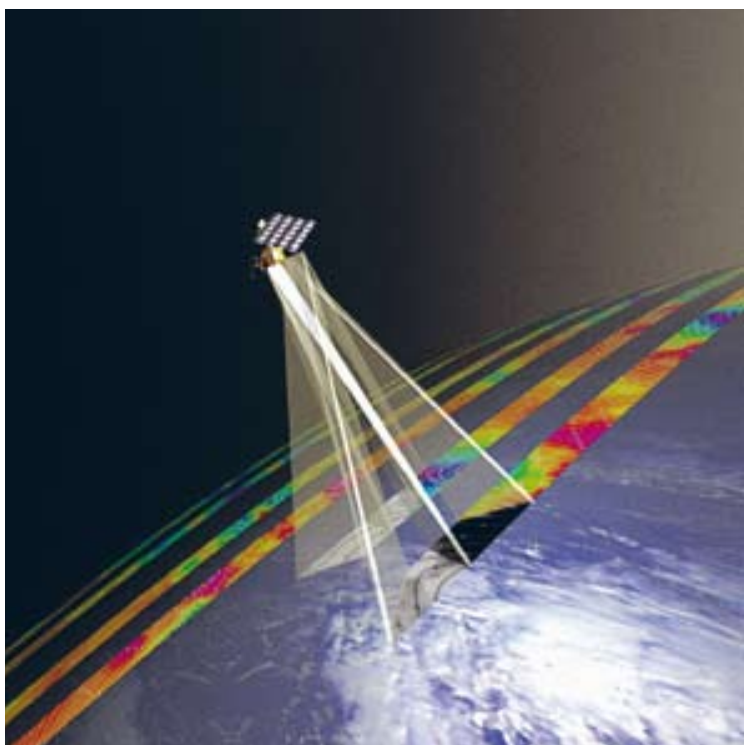

\section{Introduction}

Continuously monitoring and studying the changes in the Greenland and Arctic cryosphere - both sea ice and the Greenland Ice Sheet - are crucial for assessing the impact of and adapting to climate change in a timely and proportional manner, not only regionally in the Arctic but also on a global scale, such as a rising sea level and changing ocean currents. In-depth understanding of the dynamics of the Arctic cryosphere and its role in the global climate system are therefore needed.

However, the models and prognoses for the climate trends in the Arctic are still uncertain. Hence, obtaining more accurate and consolidated data about changes in the cryosphere is a pressing need to improve the quality of the predictions of both regional and global climate models.
Further, the prospect of melting sea ice opening up the Arctic presents new opportunities and challenges. Increasing areas of open water will create new opportunities for commercial fishing, extraction of hydrocarbon reserves beneath the sea floor and marine transport routes. Taking advantage of these opportunities and managing the associated risks and challenges requires establishing a reliable infrastructure for navigation in the Arctic Ocean and an operational service for monitoring Arctic sea ice.

\section{Challenges and solutions}

Developing space-based infrastructure for monitoring the cryosphere

Current climate models have not been able to predict very well the changes observed in the Arctic. There is therefore an international focus on the need to provide reliable, secure and continuous monitoring of the Arctic cryosphere.

The only viable solution for measuring changes in the vast, harsh and remote stretches of sea ice and the Greenland Ice Sheet is to use space-based systems. Satellite instruments can provide a precise and updated overview of the trends in the cryosphere that cannot be obtained in any other way. Hence, a key technological challenge for ensuring adequate impact assessment and adaptation is to develop and maintain infrastructure in space for systematic cryosphere monitoring. This includes both deploying the necessary instruments - laser, radar and gravity sensors - in space and refining the methods for processing satellite data to obtain the necessary accuracy and reliability.

An added benefit is that establishing continuous operational satellite monitoring will enable researchers to empirically assess whether the implemented mitigation measures deliver the expected effects. 
The necessary technology for establishing infrastructure for systematic space-based monitoring of the cryosphere already exists. The main challenge is to take the necessary political decisions and commit the resources for establishing the infrastructure.

Systems for marine navigation and operational monitoring of sea ice

Paradoxically, the decrease in the extension of the Arctic sea ice will require intensified navigation service and monitoring of the sea ice because of the expected increase in marine transport and offshore activities. This poses two special challenges in developing technology:

- establishing a reliable infrastructure for navigation in the Arctic Ocean; and

- developing an automated system for continuously mapping sea ice and icebergs.

The existing global satellite navigation systems - such as the GPS (Global Positioning System) -provide limited coverage in the northernmost latitudes. Ensuring safe passage of ships and the safety of offshore activities requires combining new ground- and space-based infrastructure supplemented with new and improved methods for data processing. The new European satellite navigation system Galileo will be a key element, but supplementary ground-based infrastructure needs to be established in the Arctic.

\section{Implementation issues} Time frame

There is a pressing need to establish the necessary infrastructure to ensure timely adaptation to the effects of the accelerating changes in the cryosphere. Such projects have a minimum lead time of 3-5 years, so the necessary political decisions need to be made at the national and European levels as soon as possible.

\section{Partnerships and actors}

Because of the large scale of the project and the international nature of the field, the changes in the Arctic cryosphere can only be continuously monitored based on international cooperation.

The European Union and the European Space Agency should play a key role establishing an extensive, operational space-based infrastructure that can be used by all European Union countries, including Denmark. This infrastructure should be implemented as part of the joint Global Monitoring for the Environment and Security (GMES) initiative of the European Union and the European Space Agency.

The services for marine navigation and operational monitoring of sea ice should be implemented at the regional level, supported by both public and private stakeholders.
Policy and measures

Decisions at the international level - not only the European Union and the European Space Agency but also forums including all Arctic actors - are necessary for managing the associated risks and challenges and for taking advantage of the opportunities that arise as a result of climate change. At the national level, European political decision-makers must push to put cryosphere monitoring on the agenda of the GMES initiative and ensure that government funding is provided to support the associated national activities.

In order to obtain the optimal science return from Denmark's exploitation of the common European space-based infrastructure, the Danish contribution to the European Space Agency should be increased to the average level of the contributions from the other 17 European Space Agency Member States, which are determined based on gross domestic product.

\section{Reliance on and relations with other sectors}

The marine navigation services and the automated system for operational monitoring of sea ice should be developed in cooperation with private companies that are involved or are contemplating becoming involved in offshore activities and marine transport in the Arctic region. 


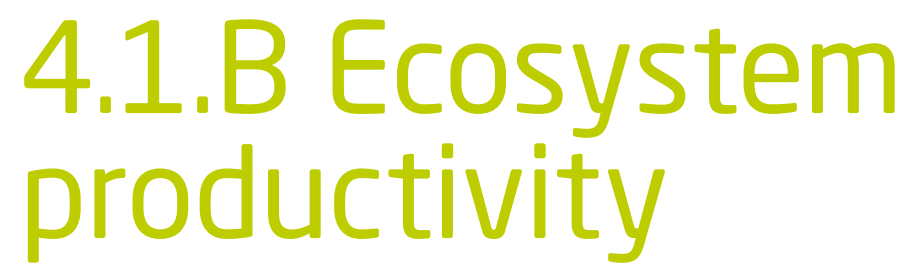

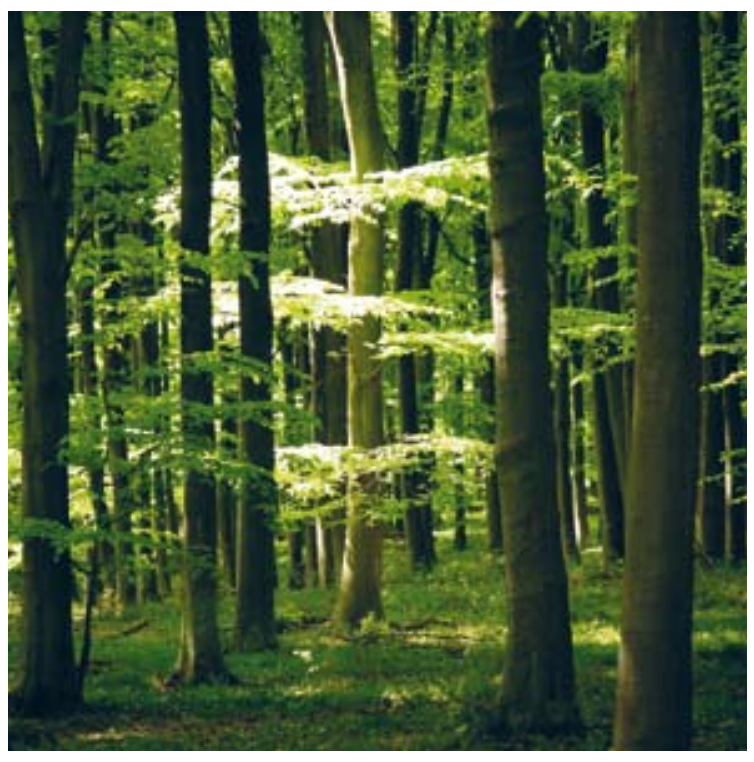

Introduction

Gross fluxes of greenhouse gases (both carbon and nitrogen) due to marine and terrestrial productivity in biogeochemical processes are 20-30 times greater than fluxes due to fossil fuels and strongly affect global carbon budgets. Biological uptake and release are changing, but there is uncertainty about many of the processes, what controls them and what the net effects will be.

Many resources are being deployed to develop technical means of ameliorating greenhouse-gas flux, especially when a product or process can be marketed, such as cleaner cars or more energy-efficient transport. Comparable resources should be deployed on biogeochemical processes because the trajectory of future global greenhouse-gas emissions strongly depends on actions to ensure that biological fluxes do not change in adverse ways. Success in controlling the trajectory of greenhousegas emissions requires rapid and continuing improvement in knowledge of biogeochemical processes to guide such action most effectively. If effective action is not taken to limit or reverse adverse changes due to biological processes, then humans with low emissions will be living in a high-emission world (Fig. 2).

\section{Challenges and solutions}

All terrestrial systems are affected by climate change via the high temperature sensitivity of physiological processes and the dependence of primary productivity on soil water availability in many areas. Fish production and fisheries in tropical and subtropical areas will be affected negatively, putting more pressure on low-income areas, while in subarctic and arctic environments production and catch are expected to increase. The oceans will likely become more acid, but the exact nature and effects remain largely unknown. In both the oceans and on land, species or a biota may naturally (physiologically and genetically) adapt to climate change or avoid changing environmental conditions by migrating or shifting distributions, but the rates will often fail to keep up with the unprecedented pace of global climate change.

\section{Fundamental challenges}

Food needs to be produced for 9 billion people while competition increases for natural resources for such purposes as energy, carbon storage, nature conservation and recreation.

Other fundamental challenges include avoiding entering the phase in which net land carbon fluxes change direction and feed back positively on global climate change. This requires drastically reducing global $\mathrm{CO}_{2}$ emissions from fossil sources. All technical and political solutions to mitigate or adapt to climate change should consider a holistic approach to ensure that solutions in one area of human activity do not counteract efforts to mitigate or adapt to climate change in other areas. 
Fig. 2. Global carbon cycle showing main annual fluxes: "natural" fluxes in black and "anthropogenic" fluxes in red. Annual gross terrestrial primary production (GPP) is 120 gigatons of carbon per year (GtC $\cdot \mathrm{yr}^{-1}$ ). Annual gross marine primary production is $50 \mathrm{GtC} \cdot \mathrm{yr}^{-1}$. Almost all the carbon fixed in primary production is released in respiration, but some is sequestered in terrestrial vegetation and in the deep ocean. The atmospheric carbon content and all cumulative fluxes since 1750 are as of the end of 1994.

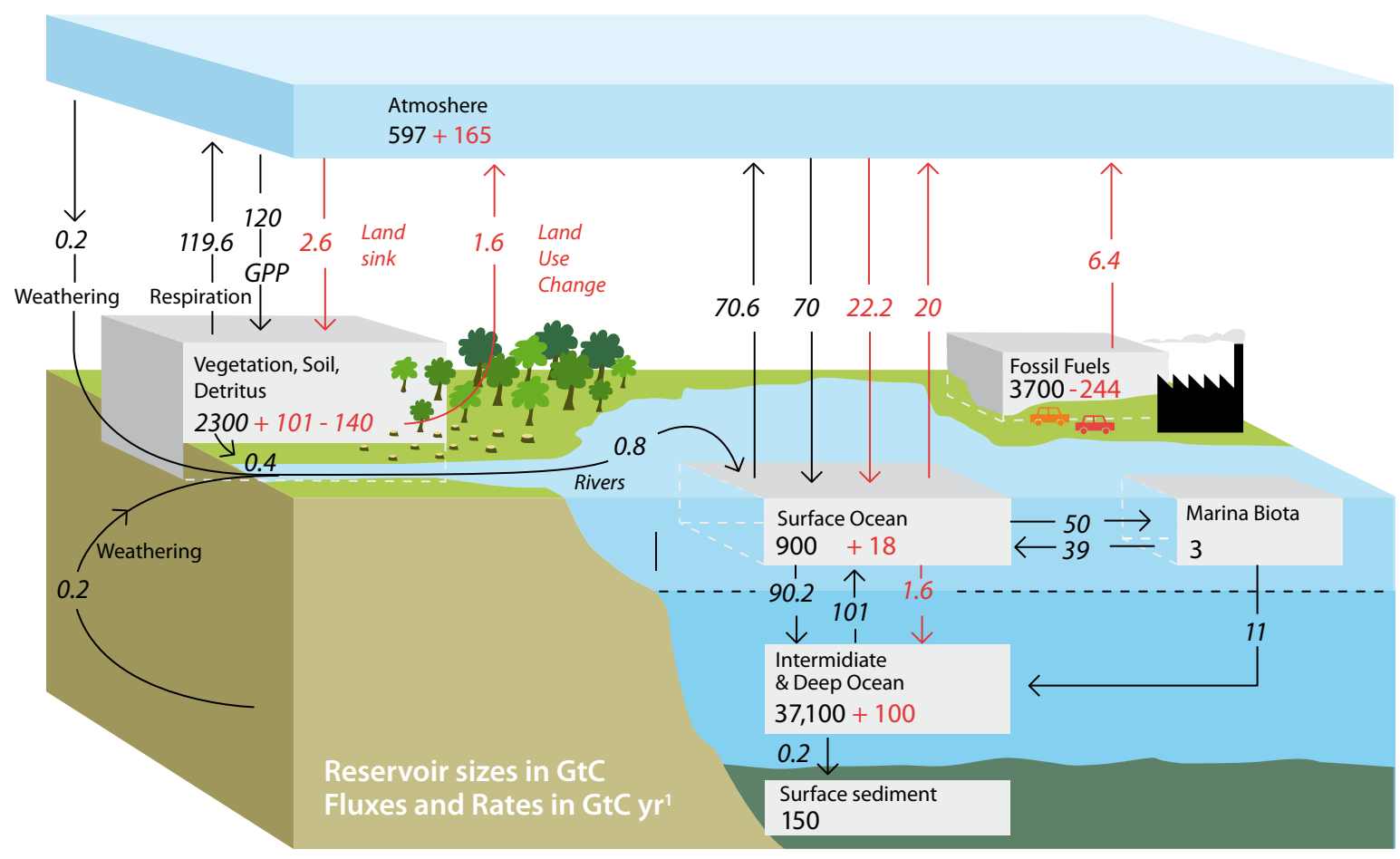

Source: Solomon S et al, eds. Climate change 2007: the physical science basis. Geneva, IPCC, 2007.

\section{Sequestering greenhouse gases}

Oceans and the land have similar potential to contribute to sequestering greenhouse gases. The maritime sink depends mainly on vertical mixing, resulting in uptake or release of $\mathrm{CO}_{2}$ according to the difference in partial pressure between the ocean surface and the atmosphere. Both the solubility pump and the biological pump play a role in this, although the net contribution of the biological pump appears to be relatively minor. Stimulating the biological pump through iron fertilization, for instance, could potentially increase ocean sequestration significantly but with side effects that are not yet resolved. Fisheries already strongly influence the marine ecosystem, and the manipulation of oceans' carbon flux via fisheries has been hypothesized and needs to be investigated further. The sequestration of $\mathrm{CO}_{2}$ and other greenhouse gases on land is much more linked to human activity and control. Land-use change from forests and grasslands to crops is the largest threat to soil organic matter, which may limit the potential for reducing the carbon footprint by increasing the use of biofuels.

\section{Nitrogen deposition, nitrogen leaching and eutrophi- cation}

Adding nitrogen to marine and terrestrial ecosystems in which net primary production is limited by the availability of nitrogen could potentially lead to increased growth and thereby sequester carbon. This might be even more relevant in a future $\mathrm{CO}_{2}$-rich world, as $\mathrm{CO}_{2}$ also acts as a plant fertilizer. However, many ecosystems already have high nitrogen concentrations, and elevated temperatures will increase the mineralization and leaching of nitrogen to groundwater and fresh water. Part of the additional nitrogen mineralized may potentially lead to additional carbon sequestration at higher $\mathrm{CO}_{2}$ concentrations, but not to an extent that will capture all additional nitrogen. Climate change therefore makes it recommendable to reduce nitrogen deposition. This will require 
regulating emissions from transport, industry and agriculture. Reducing nitrogen emissions will have many other benefits such as reduced pressure on biodiversity and will mitigate potential oxygen depletion in marine ecosystems. Similar conclusions may be drawn for other limiting nutrients such as phosphorous.

\section{Scientific challenges}

Understanding is limited for many of the processes and interrelationships that control marine and terrestrial productivity. However, action cannot be delayed until understanding is fuller or forecasting becomes more precise. Action is therefore needed based on current knowledge and understanding, which is considered sufficiently good:

- to evaluate appropriate levels of precision;

- to evaluate risks and uncertainty;

- to design robust, no-regret strategies;

- to build reflexive, responsive management processes;

- to adopt, evaluate and improve best practices;

- to analyze and explain the asymmetry of effects (between action versus inaction);

- to identify action that is necessary but may not be sufficient;

- to investigate the potential changes in marine and terrestrial productivity;

- to analyze the drivers and behavior of these large systems; and

- to identify tipping points for large and rapid changes in climate and ecological regime shifts.

Several solutions are listed; the first group includes solutions that can be implemented based on current knowledge. Solutions listed in the last group are more risky and may require further research before being implemented.

\footnotetext{
Solutions that can be implemented based on current knowledge

Managing natural systems to reduce greenhouse-gas emissions, sustain food production and provide other ecosystem services

- Avoid changing land use from natural to managed systems associated with increased soil carbon loss and/ or greenhouse-gas emissions.

- Protect and augment ocean margins (such as seagrass meadows and mangroves).

- Intensify and optimize sustainable food production (agriculture and aquaculture) on limited areas.

- Increase cultured fish and shellfish production.

- Use genetic variation and selective breeding to increase yields, produce better materials or improve the efficiency of processes.

- Limit nutrient losses and transport from agricultural production and other sources, such as by treating sewage, re-meandering streams and protecting coasts.
}

- Adopt procedures known to improve the efficiency of nitrogen use and reduce nitrogen losses and possibly use nitrification inhibitors.

- Improve fish capture technologies and improve fisheries management to reduce fishing effort and thus fossil-fuel emissions and restore fish stocks.

- Introduce flexible, adaptive and responsive modeling of natural systems and management.

Solutions mainly related to politics or other sectors

- Adopt the development and use of life-cycle analysis and quantitative sustainability assessment of all technologies, solutions and products, and for broad product categories, to include all environmental damages and costs, and price goods and services in accordance with environmental and societal costs.

Controversial or theoretical solutions that need further investigation

- Energy cropping: reducing soil carbon and humus content will affect the capacity of soil to hold water and nutrients, thereby reducing productivity and increasing the risk of soil erosion and desertification, and production of biofuels may compete with land use for food production.

- Carrying out carbon fertilization with biochar (environmental and health risk not clear).

- Increasing the numbers of particles in the atmosphere (is theoretical and the risks are not clear).

- Fertilizing coastal areas, oceans and forests (risks not clear).

- Storing carbon in the ocean (this could harm the deep sea environment and become very costly, although burial beneath the deep sea floor is ongoing).

- Blue bioenergy - land-based production of phytoplankton using agricultural or aquacultural waste as manure.

- Managing how fish and fisheries affect the efficiency of the continental shelf carbon pump (needs study and investigation).

- Using genetically modified organisms to increase food production (problems with public acceptance).

- Using growth hormones in livestock to reduce methane emissions (problems with public acceptance).

\section{Implementation issues}

The following policy measures should be implemented.

- Raise awareness for a wider debate on how to balance conservation and transformation.

- Adopt an ecosystem approach to agriculture similar to fisheries management.

- Improve local adaptation and education (of people).

- Improve and encourage agricultural products and production methods with a reduced carbon footprint. 
Research on the perturbation of natural biochemical cycles is needed because the natural fluxes of carbon are much larger than anthropogenic fluxes. Small changes in the natural balance can therefore offset other measures to decrease greenhouse-gas emissions and increase carbon sequestration.

Research is needed to bridge the gap between technology and understanding how anthropogenic activity and climate change perturb biochemical cycles. Bioenergy processes and methods for increased carbon sequestration on land and sea should be developed as a joint effort between research disciplines to ensure that the net gain in energy and greenhouse-gas balance is sufficient.

Many solutions are ready to implement immediately (as listed above). 


\subsection{Infrastructure and climate change}

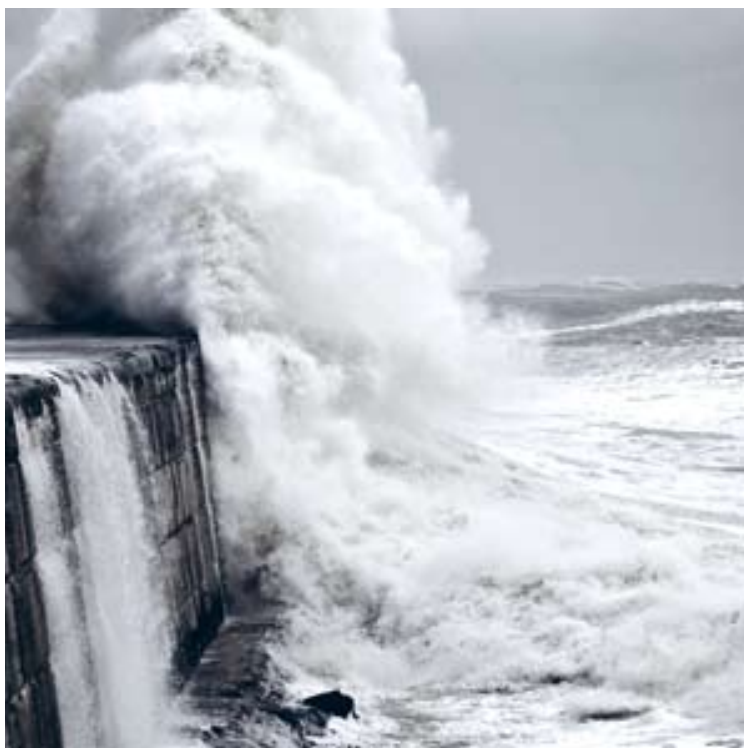

Introduction

Infrastructure in transport and utilities worldwide is a result of massive investment. Infrastructure is the key to the well-being of society, and even rare and/or intermediate interruptions have great effects. Design of infrastructure is adapted to local climate conditions, and climate change increases the vulnerability of the infrastructure and thus the risk of interrupted service and/or deterioration of the infrastructure components.

\section{Challenges and solutions}

The technical lifetimes of infrastructure systems (excluding airports) are typically long: comparable to the time frame for assessing climate change. However, almost all infrastructure is designed without considering how climate change affects the design criteria. The effects of climate change are still very uncertain, but action must be taken very soon and under substantial uncertainty. The key challenges for infrastructure and climate change are listed below for new and existing infrastructure followed by discussion on how to address the challenges.

Design of new infrastructure and spatial planning New infrastructure has traditionally been designed by considering historical information on key variables. The industrialized countries have extensive data covering climate information, allowing the design level to be optimized in detail. However, climate change will substantially affect some of these variables, notably those related to the water cycle (sea level, rainfall intensity and snow cover). Establishing suburbs in areas close to sea level or flood plains will result in either accepting more frequent flooding in the future or accepting major protective measures to protect the investment. Considering the effects of climate change in the design process is therefore of paramount importance, but design guidelines currently have little or no information on how to incorporate this knowledge. Rather fragmented collaboration between the relevant stakeholders is a further barrier to smooth implementation of new knowledge.

\section{Retrofitting existing infrastructure}

In industrialized countries, the operation and maintenance of existing infrastructure have been optimized in recent decades by improving measurement and modeling based on a collaborative effort by all stakeholders, from regular maintenance to research. In combination with increased demand for infrastructure capacity, this has led to a systematic reduction of "passive" redundancy and spare capacity in infrastructure. Difficulty in obtaining suitable cost-recovery schemes for maintaining current service levels has further driven this process. As a result, the planning time horizons are much shorter than previously. Maintaining current service levels, including the effects of climate change, requires changing management to handle the substantial increases needed in investment in infrastructure to cover both improved maintenance of existing systems and increased capacity to manage the effects of climate change. The engineering 
societies are unlikely to be able cover the new demand for some of the key sectors, and greater focus on educating new engineers is therefore needed. Further, the public has been very interested in how the effects of climate change should be considered by including measures to improve resilience to climate change in new and existing urban areas.

A few countries have performed systematic and detailed studies on the effects of climate change and constructed frameworks for identifying suitable adaptation strategies. The Stern review on the economics of climate change published in 2006 facilitated much better understanding between the engineering and economic societies. At the project level, inferring which alternatives are "climate change-proofed" and which alternatives are only suitable on a short time scale is often possible. However, many barriers exist for implementing the optimum solutions; one is that including climate change considerations at the project level is not required.

There are three main fields for research.

- Better models for projecting the effects of climate change, both forecasting scenario development and scaling the effects to the relevant temporal and spatial resolutions.

- Technical adaptation solutions based on new and improved technology. Key technologies include: construction material science for secondary and inhomogeneous materials (such as concrete and pavements), new construction materials and methods (such as super-glass and super-light construction), models for predicting service life (such as life-cycle analysis and structural monitoring), hydrodynamic models (such as flooding, coastal protection and sewerage systems), advanced infrastructure technology (such as high-speed trains and coastal defense systems), underground construction (such as tunneling and geotechnical sciences) and construction management (such as integrated design, partnerships and robotics).

- Socioeconomic and technical evaluation of suitable adaptation strategies for climate change adaptation should be included in a risk management framework that will highlight the advantages and disadvantages of approaches to adaptation. This will enable national legislation that promotes suitable decisions on all levels from individual projects to national action plans regarding planning and constructing infrastructure and, if incentives are implemented, will also stimulate innovation in the infrastructure sectors.

\section{Implementation issues} Time frame

Because infrastructure has long technical lifetimes, a strategic outlook must be taken. Considering the goal of nearly no greenhouse-gas emissions beyond 2050 in developed countries, long-term infrastructure solutions must include this perspective now. If adaptation can be carried out during regular upgrading, the cost is much lower than if specific adaptation is carried out. For example, the cost of specific adaptation action in upgrading sewerage systems is assessed to be 10-20 times the cost of upgrading in the regular renovation of the sewers. This also applies to other sectors. For developing countries, the problems of lack of proper climate projections or even current extreme climate conditions are major issues that need to be addressed rapidly to take full advantage of new technology.

\section{Policies and actors}

The privatization of utility companies in Europe has reduced the focus on the long-term performance of infrastructure. Extensive mass-media coverage followed by political action because of flooding in urban and rural areas or lack of electricity for months indicates that the general public may want a change of paradigm towards optimization over longer time frames. 


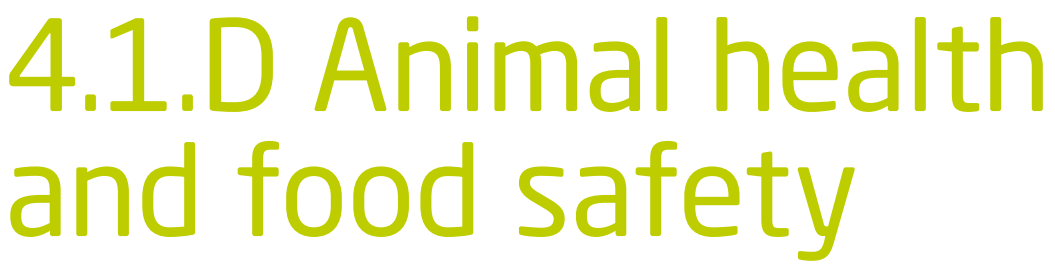

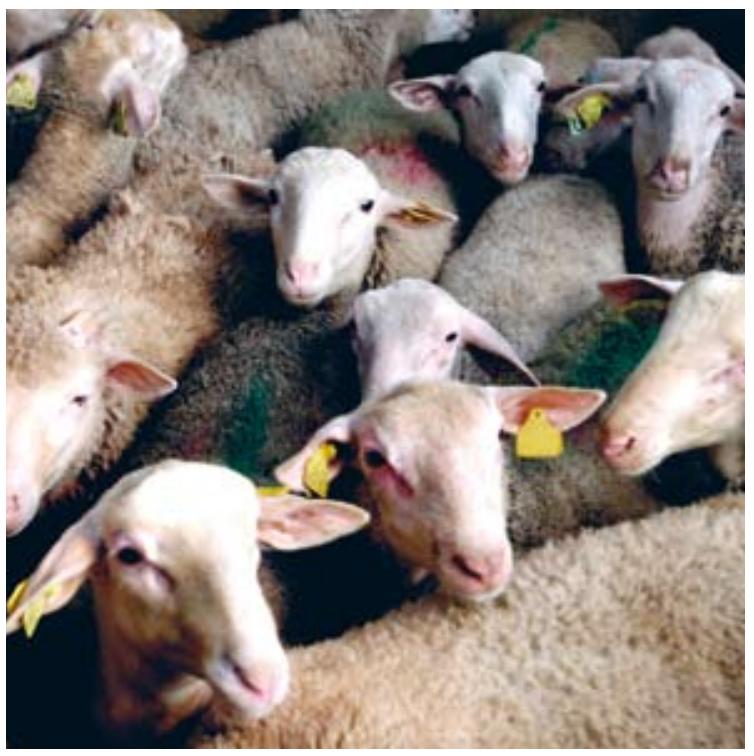

\section{Introduction}

Climate change is expected to alter the pattern of endemic infectious diseases of humans and animals, and new infectious diseases may emerge or re-emerge in Denmark. This is illustrated in part by the seasonal variation in the incidence of foodborne bacterial infections in humans, with considerably more cases in the summer than in the winter. Further, in recent years several new infectious diseases have emerged in animals and humans.

Knowledge so far about the causes and effects indicates a complex association with climate, environmental and/or behavioral factors.

\section{Challenges and solutions}

The elements involved in the development of emerging diseases comprise biological (including genetic) factors, ecological factors, physical environmental factors and social, political and economic factors. These factors may interact in a complex way that varies according to disease, region and time. Thus, an interdisciplinary approach must be developed to better understand the interactions between these elements and to develop predictive models and, thereby, to respond early and efficiently to infectious disease threats.

Although complex, the following examples indicate how climate affects human and animal diseases in Europe and worldwide.

Bluetongue, a midge-borne viral disease of ruminants, emerged for the first time in northern Europe in 2006, during the hottest summer on record for that region and following nearly a decade of anomalously warm years. In 2007, the disease was reported in nine European countries, including the United Kingdom and Denmark, during a massive outbreak that affected thousands of farms.

Ticks that carry viruses known to be associated with encephalitis have been found at increasingly higher latitudes in northern Europe. A recent study in Denmark revealed a marked shift in the distribution of the tick-borne encephalitis virus.

An outbreak of Vibrio parahaemolyticus gastroenteritis, associated with human consumption of raw oysters from Alaskan waters, extended the northernmost documented source of shellfish carrying this pathogen by $1000 \mathrm{~km}$. Vibrio parahaemolyticus had not been found in oyster beds in this region before 2004 .

Several reports have indicated that El Niño-Southern Oscillation affects the transmission of vector- and non-vector-borne diseases such as malaria, dengue fever, cholera and Rift Valley fever.

Several studies have found that outbreaks of Salmonella and Campylobacter food poisoning are closely related to temperature. 
Concerns in freshwater and marine wildlife, due to recent increases in incidence and/or geographical range, include Ranavirus, a skin-destroying viral pathogen that infects North American and European amphibians, and viral hemorrhagic septicemia, a viral disease associated with large-scale mortality of many common fish species, including marine species. The virus can survive in warm and cold water and in estuarine and marine water as well as in freshwater systems.

The complexity of the climate system makes it inherently difficult to develop robust models for risk assessment and/ or forecasting changes in infectious disease incidence resulting from climate change.

Meeting these challenges requires strengthening and/or revising activities in several areas, including the following.

\section{Knowledge and technologies}

- Research is needed on the links between climate and other factors and infectious diseases.

- Disease transmission models need to be developed further to assess the risks posed by climate change and other changes.

- Epidemiological surveillance programs should be strengthened, including increased wildlife monitoring.

- New technologies should be developed: rapid, sensitive and cost-effective methods for detecting diseases and pathogens; new vaccines; decontamination and water purification.

Observational, experimental and modeling activities are interdependent and should progress in a coordinated fashion, and research on climate change and infectious disease links requires interdisciplinary and international collaboration.

Systems

- Early warning and emergency response systems.

- Risk communication.

Behavior

- Application of good practices in animal and food production.

\section{Implementation issues}

\section{Time frame}

The infectious diseases that are most likely to change in prevalence due to climate change (in Europe) need to be identified and ranked. The identification scheme should also include the likelihood of new diseases emerging. This should be done during the next 12-18 months.

Based on the above ranking, relevant surveillance programs should be initiated in the next 12-24 months.
Research to investigate the effects of climate change and other factors on animal diseases and human diseases associated with animals and food needs to be strengthened and initiated. National research programs should complement international activities and focus on the most important national and regional problems (in the next 5-10 years).

In addition, research and innovation need to be strengthened to develop methods for rapidly and inexpensively detecting and characterizing infectious agents in animals, food and the environment, and vaccines and purification technologies need to be developed (in the next 5-10 years).

Based on research and surveillance results, improved models should be developed to produce estimates of risk and to predict the effects of climate change on the prevalence and incidence of priority infectious diseases (in the next $2-5$ years).

As the results of these initiatives evolve, the national contingency plans and national surveillance systems should be updated and adjusted to account for potential changes (in the next 2-10 years).

\section{Partnerships and actors}

The most important diseases should be identified and ranked in collaboration between universities, authorities and the private sector. It should further be considered whether these activities should include neighboring countries.

Research on the associations between climate change and infectious disease should ideally be carried out in international collaboration, such as a part of European Union programs, combined with national programs that complement the international activities and focus on national and regional problems.

Predictive models and risk assessment models should be developed in international collaboration and in partnership with international organizations: the World Health Organization, the Food and Agricultural Organization of the United Nations and the World Organisation for Animal Health).

\section{Policy and measures}

Policy decisions and interventions must be made at the international level to be effective, as most of the causes of the changes in disease patterns are related to transboundary conditions. National efforts to adapt to climate change, including adjusting national contingency plans, preparedness and surveillance systems and managing the associated risk, should involve authorities and research institutions as well as agriculture and the food industry. 
(1)

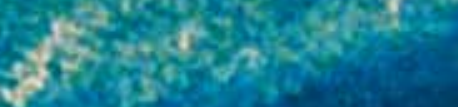

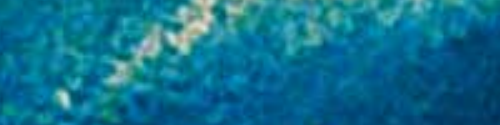

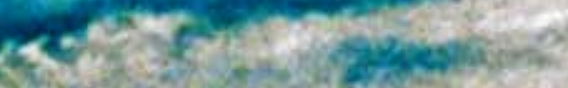
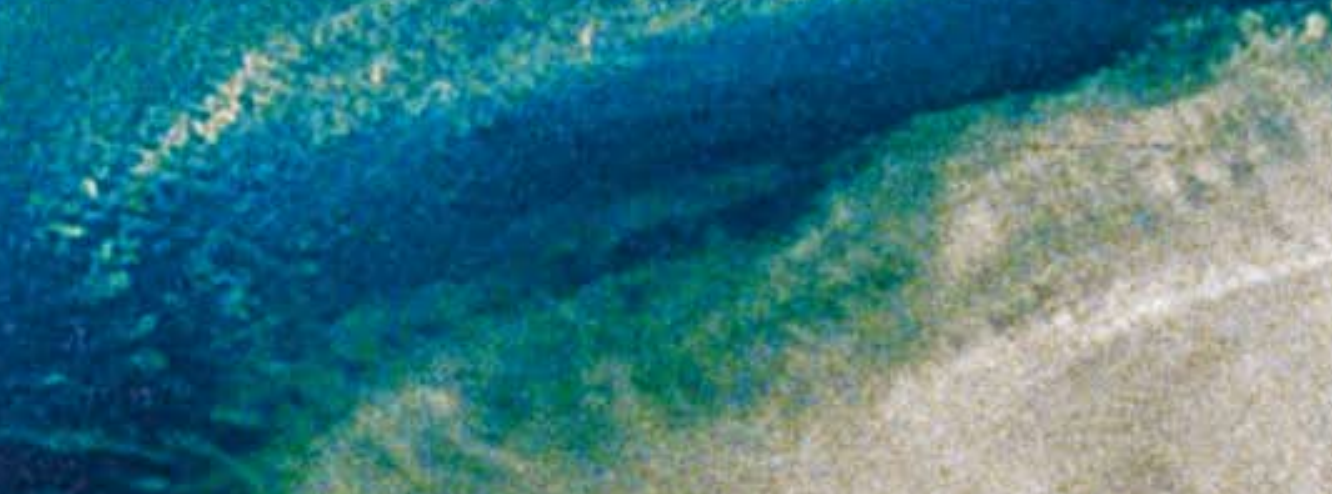

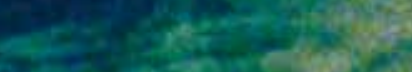

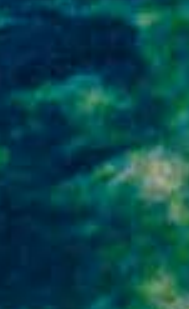

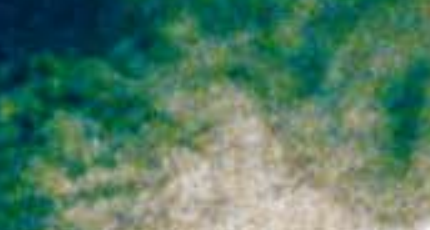
207.

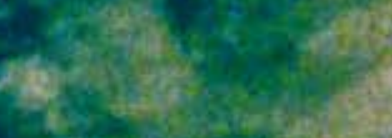
$26 x^{2}+2$
$\lim ^{2}+x^{2} x^{2} x^{2}$

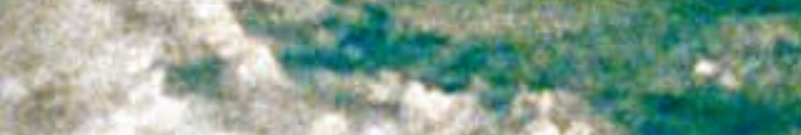

25.

As

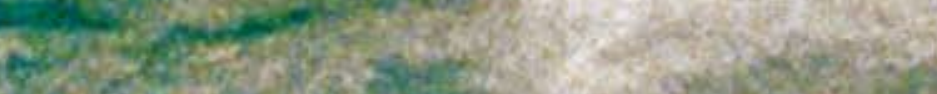

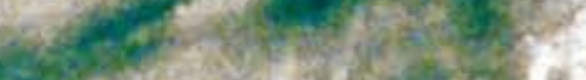

20

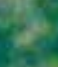

seiv.

C.?

$+60 \times$

(8)

at
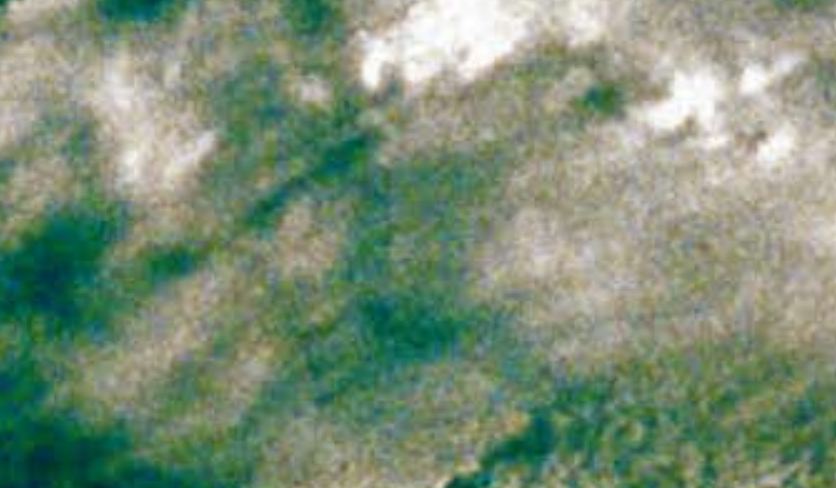

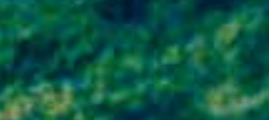

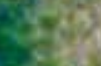

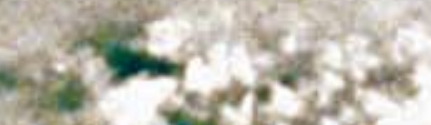

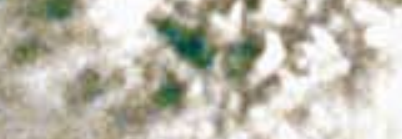


$2 \times 3+2-2 x-1$ 4

\section{Partnerships for innovation and deployment}




\section{Partnerships for innovation and deployment}

The workshops have focused on sustainable energy systems and climate change adaptation, and sections 3 and 4 have provided conclusions and recommendations on these topics, suggesting technology tracks and actions to accelerate the development and deployment of technology.

All workshops concluded that no single policy instrument or policy-making level is sufficient to address this complex issue. The climate challenge needs to be addressed as broadly as possible. A narrow focus on science policy or technology policy alone is inadequate. The climate challenge needs to be broadened to a general innovation policy focusing on the market (such as standardization, regulation and public procurement) and networks (public-private partnerships, research, development and deployment alliances etc.). Thus, the comprehensive innovation policy should include science and technology policy and stimulation of markets and learning outside the companies based on high technology.
Moreover, the climate challenge needs to be addressed from many angles. Policy-making will have to take place at multiple levels: the global level, such as the Kyoto Protocol and the United Nations Framework Convention on Climate Change, including COP 15; supranational, such as the European Union and the African Union; the national level ; and the local level: municipalities, cities and local communities. A successful transition requires action at all levels.

The workshops however, have shown consensus on several recommendations structured as follows:

- rules and regulations set by public authorities;

- development of science and technology;

- the demand side of technology; and

- coordination of efforts, resources and capability. 


\subsection{Rules and regulations set by public authorities}

The main conclusion for many of the fields of technology is that public regulations and rules should play an important role. The rules should set mandatory standards for products and services imposing maximum emissions of greenhouse gases. Legislation and regulatory requirements (such as removal of $\mathrm{NO}_{\mathrm{x}}$ and removal of chlorofluorohydrocarbons) have driven much progress in environmentally sound products and services. A precise public policy action plan, including globally applicable regulation and rules and associated appropriate enforcement of the rules, is considered mandatory for achieving the greenhouse-gas reduction targets, and developing and implementing technology sufficiently rapidly requires ambitious rules and regulation.
However, setting the rules and regulations requires a sufficiently sound knowledge base. Generally, the technology options are wide and the development tracks are difficult to predict. This requires an adaptive approach in which the requirements gradually become stricter. Setting realistic but ambitious standards that reduce greenhouse-gas emissions requires close collaboration and efficient flow of information between public authorities, science and business. 


\subsection{Development of science and technology}

As mentioned previously, radical technological changes are needed to develop new sustainable energy systems. An important part of a policy framework for climate change technologies is an ambitious and advanced policy on knowledge. This requires enhanced efforts in strategic research, in basic science and in the capability of universities and other institutions developing knowledge and technology to manage these new, substantial challenges. However, research and development efforts need to be tailored to the objective and the structure of the problem. The following section lists recommendations on improved research and development capacity in a global context.

\section{Strong and persistent efforts in basic science and technology}

Enhanced international research efforts in basic science and technology are necessary. Technological breakthroughs are necessary to solve key long-term challenges for developing a carbon-neutral economy. The main examples are loss-free electrical power transmission, energy storage and fusion energy. Open collaboration and a free flow of knowledge in a global perspective must be ensured and promoted.

Concerted research and development efforts are also needed for several established energy technologies, such as wind, solar and biomass energy, to drive the cost curve down and then link the development of technology to market forces. In other cases, research and development are mandatory for genuine technological breakthroughs. Several challenges simply need a technology leap (or several small consecutive leaps) to solve the challenge, such as energy transmission and mobile energy storage.

\section{Steady, coordinated efforts in strategic research and development}

Advances in several strategic research topics are essential for the rapid development and deployment of technology, including:

- renewable energy;

- high-efficiency fossil-fuel technology;

- intelligent energy systems;

- energy efficiency in buildings and industry; and

- low-carbon transport systems.

Good conditions must be created for testing, demonstrating and deploying new climate- and environmentally benign technologies. Special efforts can be made in supporting these favorable technologies by financially supporting demonstration plants involving local communities, providing tax relief for research, development and deployment expenditure for industry and creating research alliances.

Experience shows that stop-and-start trends in government expenditure on research and development keep efficiency from being maintained in the involved institutions. Basic research, strategic research and large-scale demonstration facilities will require government support over relatively long periods.

\section{Investments in education and mobility}

Education should be invested in at all levels, from primary to higher education and continuing education and training. High-level research and education must develop extremely qualified personnel who can support innovation. Personnel should be aware of and qualified for intersectoral and interdisciplinary collaboration. Competencies need to be developed in the construction and maintenance sector to enable rapid and reliable deployment of new and highly integrated technologies. Mobility in staff and educational knowledge should be improved. Exchange between universities could be encouraged by creating exchange programs for researchers and $\mathrm{PhD}$ fellows. 
Enhanced ability for universities to form and manage strategic partnerships with industry and with other universities

Universities and science centers should develop management and funding capacity to join long-term strategic partnerships with other universities and with industry. Universities should develop capacity to foster individual, innovative and groundbreaking research in a bottom-up structure and the capacity to undertake long-term strategic research and development using costly large-scale research infrastructure.

\section{Strengthen entrepreneurship and technology transfer measures}

Many inventions and developments will take place in large well-established companies, but measures should be taken to ensure support for small-scale start-ups and new and emerging businesses. Universities have a role in supporting these activities by including relevant capacity in their degree programs. Universities should also offer support throughout the innovation chain, including discovery, patents, proof of concept, incubator phases and the demonstration-phase takeover.

Further, financial frameworks such as dedicated venture capital and high-risk loans have an important role in facilitating the formation of new businesses and business areas based on climate change technologies. Facilitators could be preseed capital, proof of concept, proof of business programs, proactive greentech business incubators and science parks, start-up and early-stage business management consultancy services and coaching programs.

\section{Twinning arrangements and social entrepreneurship} Academic training and science environments in developing countries should be supported by twinning arrangements with universities in industrialized countries. Such agreements could be linked to national business or development agreements such as social entrepreneurship programs. Developing and adapting climate technology to specific regional needs are envisaged to be core issues, but sustainable use of resources and new and innovative regional resources for local production could be highly productive collaborative topics of mutual benefit.

\section{Strengthen the scientific basis for technology assessment} and for scientific advice

Technology assessment and advice on road-maps for implementing carbon-neutral technology require deep insight into technology options and the capacity to build quantitative models, considering the strong interdependence between sectors of the economy. The effort could include topics such as developing national appropriate mitigation action in practice. The technology options and their economic viability will change over time, and they will be quite different for different countries. Insight and numerical tools need to be developed - together with monitoring technology to continually assess the climate model predictions and whether the hypothesized effects of the mitigation measures implemented are being realized on the global scale. Collaboration should be enhanced between technical universities and economics and other social sciences. 


\subsection{Supporting markets}

New climate change technologies cannot be developed and deployed based on research alone. Most of the technological development happens while companies are producing products and services for the market, and companies do not develop technologies for markets that do not exist. Governments therefore need to develop policies for creating and stimulating the markets for new climate change technologies.

Stimulating markets for new climate change technologies A broad range of policy measures can be implemented to create or stimulate markets for new climate-benign technologies:

- creating markets: examples include public procurement programs, demonstration programs and binding targets;

- subsidizing consumers or the users and operators of new technologies through investment subsidies, operating subsidies, taxation schemes, soft loans and other measures;

- creating separate markets, such as by issuing green certificates;

- supporting standardization: especially support for research and processes leading to international standardization; and

- information campaigns and product-labeling schemes such as ecolabeling.

\section{Supporting international standardization}

Research and, to some extent, industrial manufacturing are international activities, whereas creating markets and regulating market conditions are mostly national activities. Consequently, cooperating on creating international markets is much more difficult than cooperating internationally on research and development. An important measure for creating international markets is international standardization, which can promote international markets for new technologies and international competition on these markets.

\section{Stable and predictable market conditions}

As mentioned, industrial development and manufacturing do not happen for markets that do not exist. Industry must at least have clear expectations that the market will exist in the short to medium term. Policy measures must ensure stable and predictable market conditions for new climate change technologies.

The current global recession provides an opportunity to focus government funds on kick-starting the deployment of climate change technologies. Kick-starting job creation and macroeconomic stimulation are also important reasons for this. Nevertheless, such kick-starting must not be carried out at the cost of the long-term stability and predictability of the markets for new climate change technologies. 


\subsection{Improving networks and alliances: coordinating efforts, resources and capability}

These challenges require large-scale research and demonstration facilities and will require government support over relatively long periods. However, encouraging the market and creating fair competition between technologies have proven to be effective. Cost-efficient research and development funding for measures to meet the global challenges will entail several initiatives.

\section{Aligning national and international research priorities and funding lines with clearly defined goals}

National and international research efforts must be used to create synergy and collaboration where needed. Clear goals and incentives for science and industry to actively participate in joint programming activities should be set internationally. However, duplicating research and technology development activities may have positive effects, as competition is an important driver of the development of new technologies and new companies.

Enhanced ability for universities to form long-term strategic partnerships with industry and with other universities

Universities and science centers should develop management and funding capacity to join long-term strategic partnerships with other universities and industry. Universities should develop the capacity to foster individual, innovative and groundbreaking research in a bottom-up structure and the capacity to undertake long-term strategic research and development using costly large-scale research infrastructure.

\section{Formation of alliances, including science, business and public authorities}

Formal alliances with science, industry research and development and industrial production have proven very efficient in developing and deploying technology. Including public authorities in the alliance will enable the efficient flow of information.
Research, development and deployment alliances give companies an opportunity, for a relatively low investment, to buy an option in technology research that could have market potential in time. Moreover, the incentive is that industry alone previously made efforts in bringing technology to the market. Bringing stakeholders together and joining forces from the whole process of technology development from research to market can reduce the time to market for specific technologies.

Clear goals and incentives should be set for science and industry to actively participate in joint programming activities. This could be implemented in an international context in which a subset of countries with specific interest and capacity in a strategic research topic could join research, development and deployment programs. Developing shared visions and developing mutual acknowledged strategic research agendas are important tasks for such alliances.

\section{Collaboration and clusters at the regional level} Regions should play an active role in demonstrating, deploying and implementing climate change technologies. Regional policy-makers have advantages over national policy-makers because they are closer to the performing actors (companies and universities) and to the local community. Regions often get engaged because they can see economic, social and environmental benefits if they succeed in creating a viable industry based on climate change technologies. More regions need to be encouraged to follow this path. One way could be to promote green industrial clusters.

\section{Stimulating green industrial clusters}

A region can either seek to guide existing industrial clusters to shift to greener technologies or induce the formation of new clusters based on emerging green technologies. In any case, a first step is to match the region's industrial strengths with possible ways to 
promote the uptake of climate change technologies. Often the region can identify industries with technology related to the climate change technologies and thus build the development on existing competencies. The most commonly used policy instruments in promoting clusters have been supporting network activities, promoting innovation through funding research, development and deployment activities, creating a special brand for the region, attracting new firms and talent to the region, providing assistance to businesses, diffusing technology in the cluster and studying and analyzing the cluster and its needs.

\section{Large-network collaboration models}

Network activities can be built based on either existing or new relationships, from small to large conglomerates among few or many different stakeholders at the national and/or international levels. In the context of climate change technologies as mentioned previously, production and consumption entail a large, complex- and multinational system in which a variety of stakeholders from different spheres interact. Hence, policy action in this context should consider the creation of large-networks of collaborations in a meta-hub for global interaction. Such networks should be based on developing and sustaining excellence and best practices for developing, diffusing and deploying technology. A basic multi-stakeholder setting should be based on the three actors involved in an innovation system: government, industry- and universities. Such a configuration brings together legislation, production and research, increasing the possibility of dialogue and consensus in technological innovation - its production and consumption - while reducing the risk of legal, technical and economic inconsistency. Networks of networks across countries and continents could reduce the overall cost of creating knowledge and diffusing, and allocation and building resources and capability. It could therefore reduce the cost and time-to-market of new technologies, eventually accelerating the innovation process and strengthening innovation systems across countries.

A recent approach to such large networks is proposed by the European Commission through the development of the European Institute of Innovation and Technology (EIT). The working structure of the EIT is based on collaboration models known as Knowledge and Innovation Communities (KIC). KICs are highly integrated public-private networks of universities, research organisations and businesses. One of the first designated KICs is on Renewable Energy and Climate Change. 
(1)

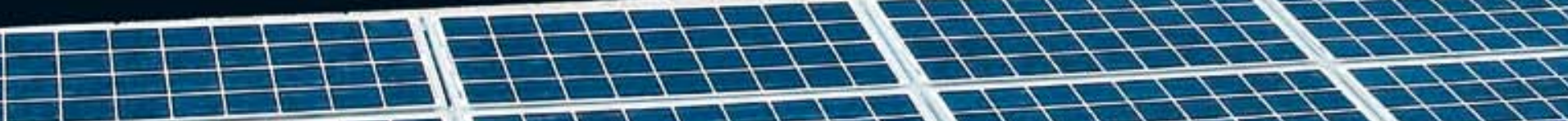

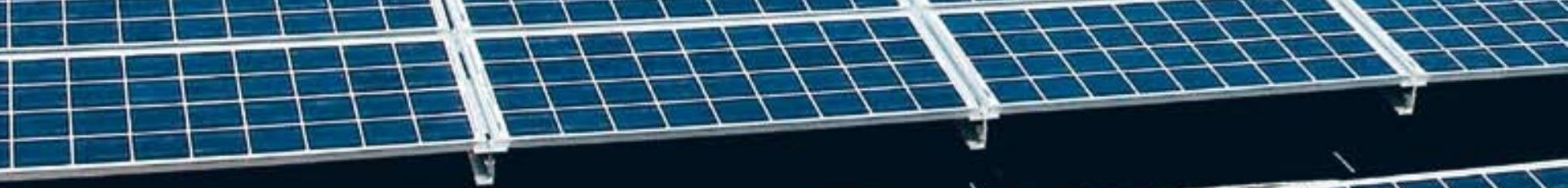

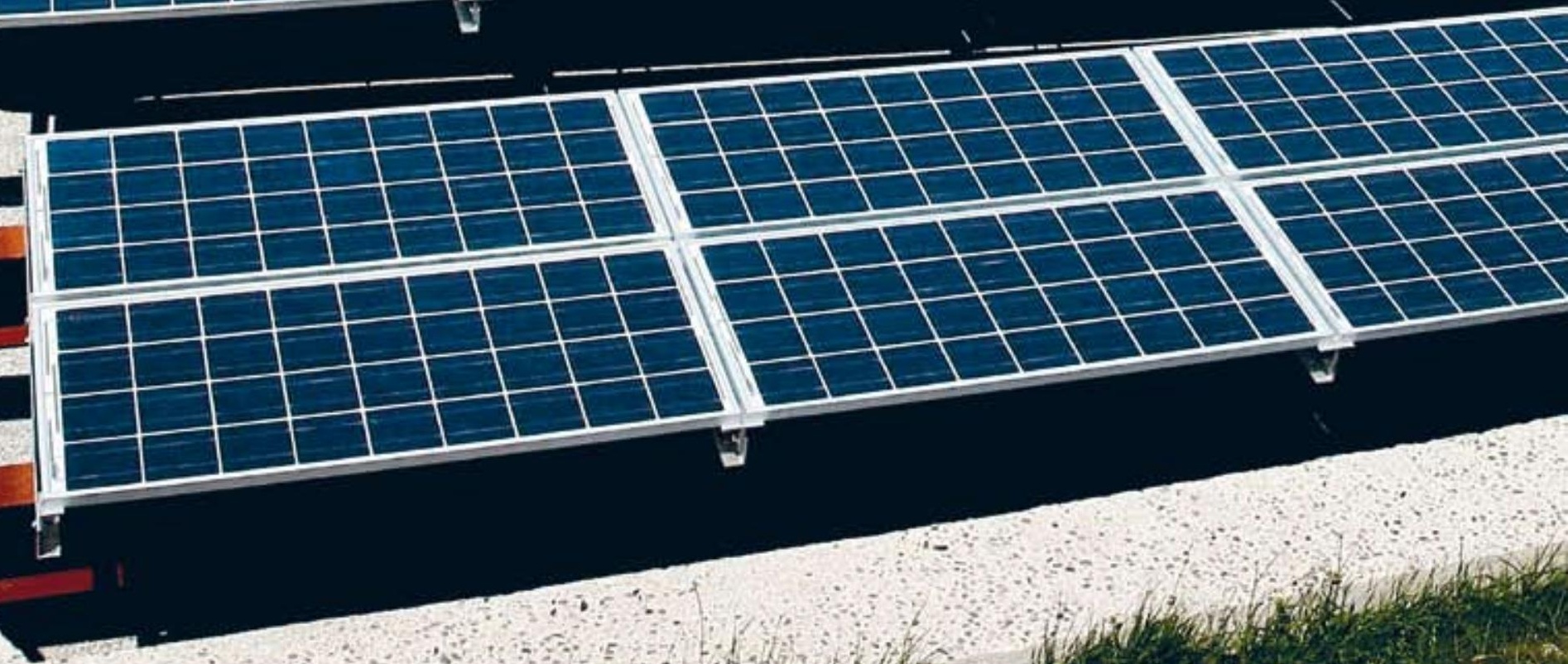




\section{DTU Climate Change Technologies}

\section{Editorial team}

Niels Axel Nielsen

Hans Hvidtfeldt Larsen

Kirsten Halsnæs

Jacob Steen Møller

Jakob Fritz Hansen

Iben Frøkjær Strand

\section{Contributors}

3.1.A Intelligent energy systems, Hans Hvidtfeldt Larsen and Leif Sønderberg Pedersen

3.1.B Sustainable energy: wind, solar and biomass, Henrik Bindslev, Hans Hvidtfeldt Larsen, Peter Hjuler Jensen, Flemming Rasmussen, Peter Hauge Madsen, Simon Furbo, Kristian O. Sylvester-Hvid, Peter Sommer-Larsen and Kim Pilegaard

3.1.C Energy storage technologies, Allan Schrøder Pedersen

3.1.D Low-emission combustion technologies, Kim Dam-Johansen and Jytte Boll Illerup

3.1.E $\mathrm{CO}_{2}$ transport and storage, Erling $\mathrm{H}$. Stenby

3.1.F Sustainable buildings, Jacob Steen Møller and Svend Svendsen

3.1.G Transport, Hans Hvidtfeldt Larsen and Leif Sønderberg Petersen

4.1.A Monitoring and climate predictions, Eigil Friis-Christensen, René Forsberg and Sune Nordentoft Lauritzen

4.1.B Ecosystem productivity, Fritz Köster, Kim Pilegaard, Andreas Ibrom, Brian MacKenzie, Claus Beier, André Visser, Iver Jakobsen, Ole Henrik Haslund, Keith Brander and Kirsten Thomsen

4.1.C Infrastructure and climate change, Karsten Arnbjerg-Nielsen, Ole Hededal and Mogens Henze

4.1.D Animal health and food safety, Henrik Caspar Wegener and Kristian Møller

Chapter 5 "Partnerships for innovation and deployment", Per Dannemand Andersen, Mads Borup, John Heebøll, Sergio Jofre, Birgitte Rasmussen, Lykke Margot Ricard and Anne Nygaard Tanner

ISBN: 978-87-990378-2-7

September 2009

Layout: winwin agency A/S · Printed in Denmark by Formula Tryxager A/S

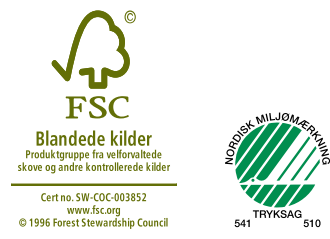




\section{DTU Climate Change Technologies}

\section{Workshop series}

During 2008 and 2009, DTU held a workshop series focusing on assessment of and adaption to climate changes as well as on mitigation of green house gasses. In the workshops, a total of 1500 scientists, government officials and business leaders have outlined scenarios for technology development and deployment and identified bottlenecks for fast track development and deployment.

\section{Workshops}

- Sustainable Buildings

- Future Energy Systems

- Sustainable Energies

- Transport - renewable energy in the transport sector and planning

- Climate Changes and Ecosystem Productivity

- Combustion, Carbon Capture and Storage

- Animal Health and Food Safety

- Infrastructure and Climate Changes

- Changes of the Greenland Cryosphere

- Risø International Energy Conference 
The DTU Climate Change Technologies programme is run by the Technical University of Denmark (DTU). It provides a firm platform for development and deployment of new technologies to climate change issues. DTU will focus on technologies which reduce $\mathrm{CO}_{2}$ emissions and can support growth and welfare while concurrently adapting to climate changes. DTU promotes co-operation between universities, industry and governments in order to accelerate the implementation of technologies and energy systems. Read more on DTU Climate Change Technologies at www.dtu.dk/climate

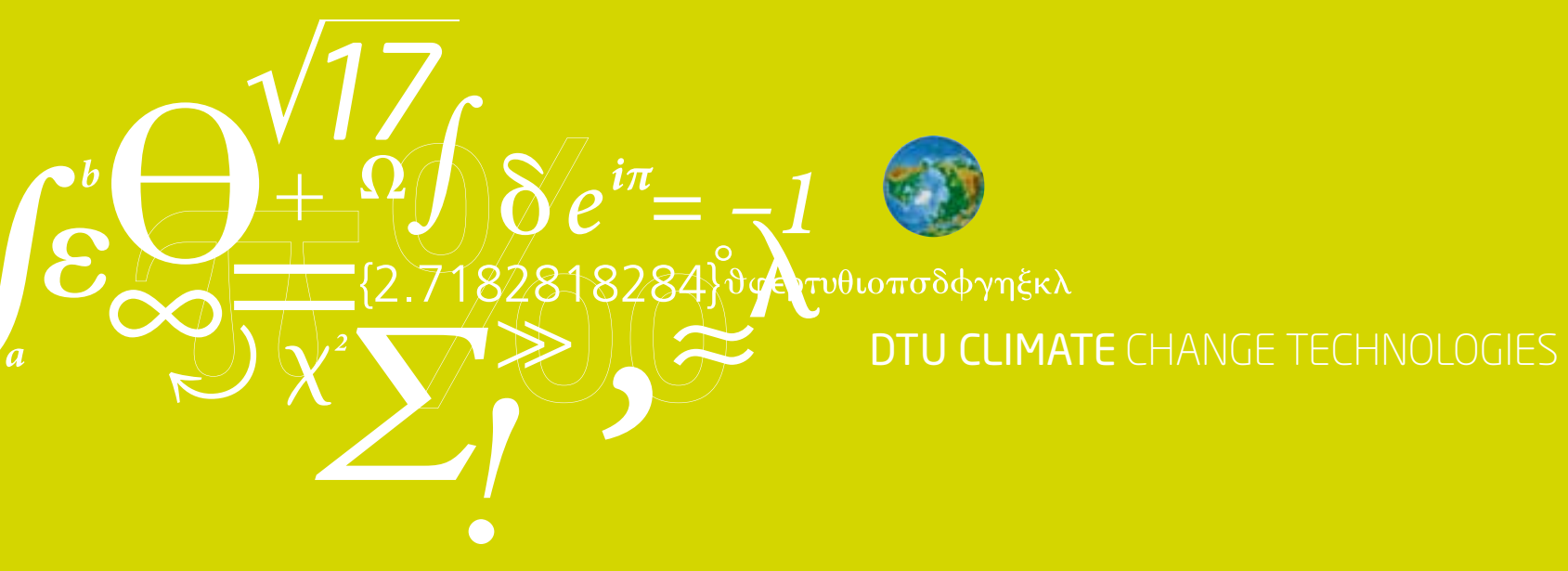

